\title{
Impact of Assimilating Future Clear-Air Radial Velocity Observations from Phased-Array Radar on a Supercell Thunderstorm Forecast: An Observing System Simulation Experiment Study
}

\author{
Yonguie Huang, Xuguang Wang, And Christopher KerR \\ School of Meteorology, University of Oklahoma, Norman, Oklahoma
}

ANDREW MAHRE

School of Meteorology, and Advanced Radar Research Center, University of Oklahoma, Norman, Oklahoma

TIAN-YOU YU

School of Meteorology, and Advanced Radar Research Center, and School of Electrical and Computer Engineering, University of Oklahoma, Norman, Oklahoma

\section{DAVID BODINE}

School of Meteorology, and Advanced Radar Research Center, University of Oklahoma, Norman, Oklahoma

(Manuscript received 30 November 2019, in final form 26 June 2020)

\begin{abstract}
Phased-array radar (PAR) technology offers the flexibility of sampling the storm and clear-air regions with different update times. As such, the radial velocity from clear-air regions, typically with a lower signal-tonoise ratio, can be measured more accurately. In this work, observing system simulation experiments are conducted to explore the potential value of assimilating clear-air radial velocity observations to improve numerical prediction of supercell thunderstorms. Synthetic PAR observations of a splitting supercell are assimilated at different life cycle stages using an ensemble Kalman filter. Results show that assimilating environmental clear-air radial velocity can reduce wind errors in the near-storm environment and within the precipitation region. Improvements in the forecast are seen at different stages, especially for the forecast after $30 \mathrm{~min}$. After assimilating clear-air radial velocity observations, the probabilities of updraft helicity and precipitation within the corresponding swaths of the truth simulation increase up to $30 \%-40 \%$. Additional diagnostics suggest that the more accurate track forecast, stronger vertical motion, and better-maintained supercell can be attributed to the better analysis and prediction of the mean environmental winds and linear and nonlinear dynamic forces. Consequently, assimilating clear-air radial velocity produces accurate storm structure (rotating updrafts), updraft size, and storm track, and improves the surface accumulated precipitation forecast. The performance of forecasts with a higher frequency of assimilating clear-air radial velocity does not show systematic improvement. These results highlight the potential of assimilating clear-air radial velocity observations to improve numerical weather prediction forecasts of supercell thunderstorms.
\end{abstract}

\section{Introduction}

Supercells can produce damaging winds, hail, and tornadoes. Numerous previous observational and numerical modeling studies show that buoyancy, vertical wind shear, and low-level moisture are important to supercell formation, maintenance, and tornado production

Corresponding author: Prof. Xuguang Wang, xuguang.wang@ ou.edu
(Rasmussen and Blanchard 1998; Thompson et al. 2003; Markowski and Richardson 2014; Wade et al. 2018). Rotunno and Klemp (1982) and Weisman and Rotunno (2000) used idealized simulations of supercell storms to confirm that the nonlinear interactions between environmental wind shear and updrafts are responsible for supercell rotation, maintenance, and propagation. Bunkers et al. (2006) examined the environments of 440 supercell events and found that long-lived supercells occur in environments with much stronger deep-layer 
wind shear. Parker (2014) explored the near-storm environments using mobile soundings from the second Verification of the Origins of Rotation in Tornadoes Experiment (VORTEX2; Wurman et al. 2012) and found that stronger vertical wind shear in the inflow near a supercell is favorable for supercell maintenance.

Assimilating environmental observations prior to the development of convection and throughout its life cycle is critical to accurate numerical weather prediction (NWP) forecasts. Previous studies have shown the importance of correctly estimating characteristics of the horizontally inhomogeneous environment for very short-range NWP forecasts of supercell (Stensrud and Gao 2010). As shown in Coniglio et al. (2016) during the Mesoscale Predictability Experiment (MPEX), the assimilation of preconvective radiosonde observations improved the depiction of low-level dynamic and thermodynamic environments and created a positive impact on the initial development and early evolution of convection. Kerr et al. (2019) found that there was significant sensitivity of supercell updraft helicity to the increase of vertical wind shear in the inflow region of the supercell after examining three cases from MPEX.

Despite numerous previous studies showing the importance of accurately representing the storm environment for the prediction of storm evolution, current observing systems lack the capability to spatiotemporally capture details of the storm environment, such as profiles of vertical wind shear and moisture that are important for convective-scale weather forecasting (NRC 2009). For example, the National Weather Service (NWS) radiosonde network has too coarse spatial and temporal resolutions, providing observations only twice per day with a mean spacing of about $350 \mathrm{~km}$ (Coniglio et al. 2016). Although mesoscale environmental monitoring networks can provide observational data at higher spatial $(\sim 50 \mathrm{~km})$ and temporal (every $5 \mathrm{~min})$ resolutions (e.g., Oklahoma Mesonet, McPherson et al. 2007), they provide atmospheric measurements only up to a height of approximately $10 \mathrm{~m}$. Vertical extension of the current mesonet (i.e., 3D mesonet) would be needed to fill the gaps (NRC 2009; Chilson et al. 2019). Recent studies of assimilating data from experimental, ground-based remote sensing networks also demonstrate such a need (e.g., Degelia et al. 2019; Chipilski et al. 2020).

Because of their ability to sample convective storms at high spatiotemporal resolution, radar measurements of reflectivity and radial velocity are most commonly assimilated for convective-scale NWP (Sun et al. 2014). A wide variety of studies have demonstrated the benefits of assimilating such radar data to convective-scale analysis and prediction (Snyder and Zhang 2003; Sun 2005; Tong and Xue 2005; Xiao et al. 2005; Hu et al. 2006;
Jung et al. 2008; Lu and Xu 2009; Dowell et al. 2011; Gao and Stensrud 2012; Thompson et al. 2012; Sun and Wang 2013; Johnson et al. 2015; Wang and Wang 2017; Degelia et al. 2018; Huang et al. 2018). However, most of these previous studies generally assimilated radar reflectivity and/or radial velocity data from precipitating regions to investigate their impacts on forecasts. Some studies (e.g., Yussouf and Stensrud 2010; Jones et al. 2015; Pan et al. 2018) indicated that assimilating clear-air radar reflectivity can suppress spurious convection around the main storm and therefore improve the subsequent forecast. Schenkman et al. (2011a,b, 2012) assimilated high-spatial-resolution low-level radial velocity observations from Collaborative Adaptive Sensing of the Atmosphere's (CASA) IP-1 X-band radars, and found the forecasts can accurately diagnose the low-level shear profile and gust front structure, as well as the subsequent prediction of mesovortex development and submesovortex-scale tornado-like vortex. Tong and Xue (2005) briefly indicated from their observing system simulation experiments (OSSEs) that, if Doppler radial velocity data in clear-air regions were available from the WSR-88D network, assimilating these data in addition to radial velocity data in precipitation regions could improve the accuracy of forecast model output.

Research exploring the assimilation of clear-air radial velocity data is limited partially because a radar has to be operated in a relatively high-sensitivity mode (i.e., longer pulse and longer update time) for radial velocity data to be useful in clear-air regions (Tong and Xue 2005; Liu et al. 2016). In the precipitation mode of WSR-88D, the radar completes 14 elevation scans in around 5-6 min, whereas in clear-air mode of WSR-88D, scanning five different elevation angles takes about $10 \mathrm{~min}$ (Sun and Wilson 2003). Therefore, for the conventional WSR-88D, the high sensitivity mode is normally not operated when precipitation exists (Klazura and Imy 1993; Melnikov et al. 2011). It implies that we cannot get $\sim 5$-min-resolution and high-quality clear-air radial velocity data from WSR-88D during precipitation. This might be one reason why previous studies only assimilate WSR-88D radial velocity data in precipitation regions.

In contrast, phased-array radar (PAR) technology would enable better sampling of the radial velocity in clear-air regions. PAR can provide a volume scan every $1 \mathrm{~min}$ or less in contrast to the $\sim 5$-min volume scan by a WSR-88D. For example, a four-faced PAR achieves rapid scanning by simultaneously scanning four $90^{\circ}$ sectors (Zrnić et al. 2007) and using agile electronic beam steering to eliminate the need for mechanical scanning (Heinselman and Torres 2011). PAR technology is particularly important for monitoring and 
forecasting rapidly evolving severe weather events (Weber et al. 2007; Heinselman et al. 2012; Heinselman et al. 2015; Bowden et al. 2015). In addition to its rapid scanning capability, PAR can adaptively steer the beam to clearair regions, adjust transmission parameters (pulse width, angular sampling interval, dwell time, etc.), and switch between clear-air and storm modes rapidly (Zrnić et al. 2019). Given the rapid and flexible scanning capability of PAR, it is expected that PAR can scan precipitation and clear-air regions using different scanning strategies, such as precipitation scanning mode in precipitating regions and high-sensitivity scanning mode in clear-air regions. Therefore, as Zrnić et al. (2019) suggested, PAR can provide useful measurements of near-storm atmospheric properties, including environmental winds in the vicinity of storms.

This study aims to address the following new questions:

- What is the impact of assimilating PAR-like observations of clear-air radial velocity on supercell forecasts if these observations are available in future?

- Does it matter if clear-air radial velocity observations are assimilated at relatively low or high frequency?

- Do the benefits of assimilating clear-air radial velocity observations vary in different stages of the storm life cycle?

- How does assimilating clear-air radial velocity observations influence the predicted storm structure and maintenance?

As an initial step to explore these questions, a series of perfect-model OSSEs using an idealized supercell case are designed and performed. Future study considering model errors and/or more realistic convective weather events is warranted. The paper is organized as follows: section 2 describes the model, simulated radar, and experiment design. Section 3 presents the results obtained from the experiments and is followed by a summary in section 4 .

\section{Method}

In this study, perfect-model OSSEs are performed to explore the benefits of assimilating clear-air radial velocity observations to supercell thunderstorm forecasts. Synthetic PAR observations are generated by perturbing the truth run from the Weather Research and Forecasting (WRF) Model.

\section{a. Creation of nature run and synthetic radar observations}

The WRF V3.4.1 is used for the truth or nature run and ensemble simulations. The truth simulation adopts the idealized run configuration with a homogeneous initial condition defined by the quarter-circle hodograph sounding described in Kerr et al. (2015) and an open lateral boundary condition (Fig. 1). The model domain is $200 \mathrm{~km}$ wide in the horizontal direction with a $2-\mathrm{km}$ grid spacing. The model adopts a stretched grid in the vertical direction with the model top at $20-\mathrm{km}$ height and an averaged vertical grid spacing of $500 \mathrm{~m}$. The Thompson microphysics scheme (Thompson et al. 2008) is used in the truth simulation. Radiation, surface-layer, land surface, boundary layer and cumulus schemes are not activated. A 3-K warm bubble with a radius of $10 \mathrm{~km}$ and a center height of $1.5 \mathrm{~km}$ is placed at the domain center to initiate a supercell thunderstorm. The reflectivity fields in the truth simulation show the first echo at $t=\sim 15 \mathrm{~min}$. At $t=\sim 70 \mathrm{~min}$, the convective cell splits, with one cell moving toward the northeast and the other moving toward the southeast. Gradually, the leftmoving and right-moving supercells are clearly separated, and the right-moving supercell is enhanced and maintained until the end of the simulation at $t=185 \mathrm{~min}$.

Synthetic PAR (radar reflectivity and radial velocity) observations are generated every $1 \mathrm{~min}$ with a full $360^{\circ}$ in azimuth. To mainly capture the inflow environmental wind fields of the right-moving supercell during the simulation, the assumed radar is located $\sim 25 \mathrm{~km}$ south of the domain center. To reduce computational expense, coarser sampling intervals $\left(5^{\circ}\right)$ are adopted. Each full volume scan consists of 14 standard elevation angles (Yussouf and Stensrud 2010) and synthetic observations are generated in radar coordinates. The highest allowed observation heights for radar reflectivity and radial velocity are $14 \mathrm{~km}$ AGL. Note that additional sensitivity experiments show that eliminating clear-air radial velocity observations above $7 \mathrm{~km}$ (Zrnić et al. 2019) does not influence the conclusions of this study due to limited availability of clear-air radial velocity observations above $7 \mathrm{~km}$ near the storm region in the current OSSE configuration due to the close range of the radar to the storm. Following Yussouf and Stensrud (2010), the reflectivity observation error is drawn from a Gaussian distribution with a zero mean and a standard deviation of $2 \mathrm{dBZ}$. A Gaussian distribution with a zero mean and a standard deviation of $2 \mathrm{~m} \mathrm{~s}^{-1}$ is used to generate radial velocity observation error where the reflectivity values are greater than $10 \mathrm{dBZ}$ (referred to as the precipitation region). Regions with reflectivity observations less than $10 \mathrm{dBZ}$ are treated as nonprecipitating (clear air) regions. To generate radial velocity observations in clear-air regions, a Gaussian error with zero mean and a standard deviation of $4 \mathrm{~m} \mathrm{~s}^{-1}$ is used.

The standard deviation ("error") values of $2 \mathrm{~m} \mathrm{~s}^{-1}$ for precipitation regions and $4 \mathrm{~ms}^{-1}$ for clear-air regions 


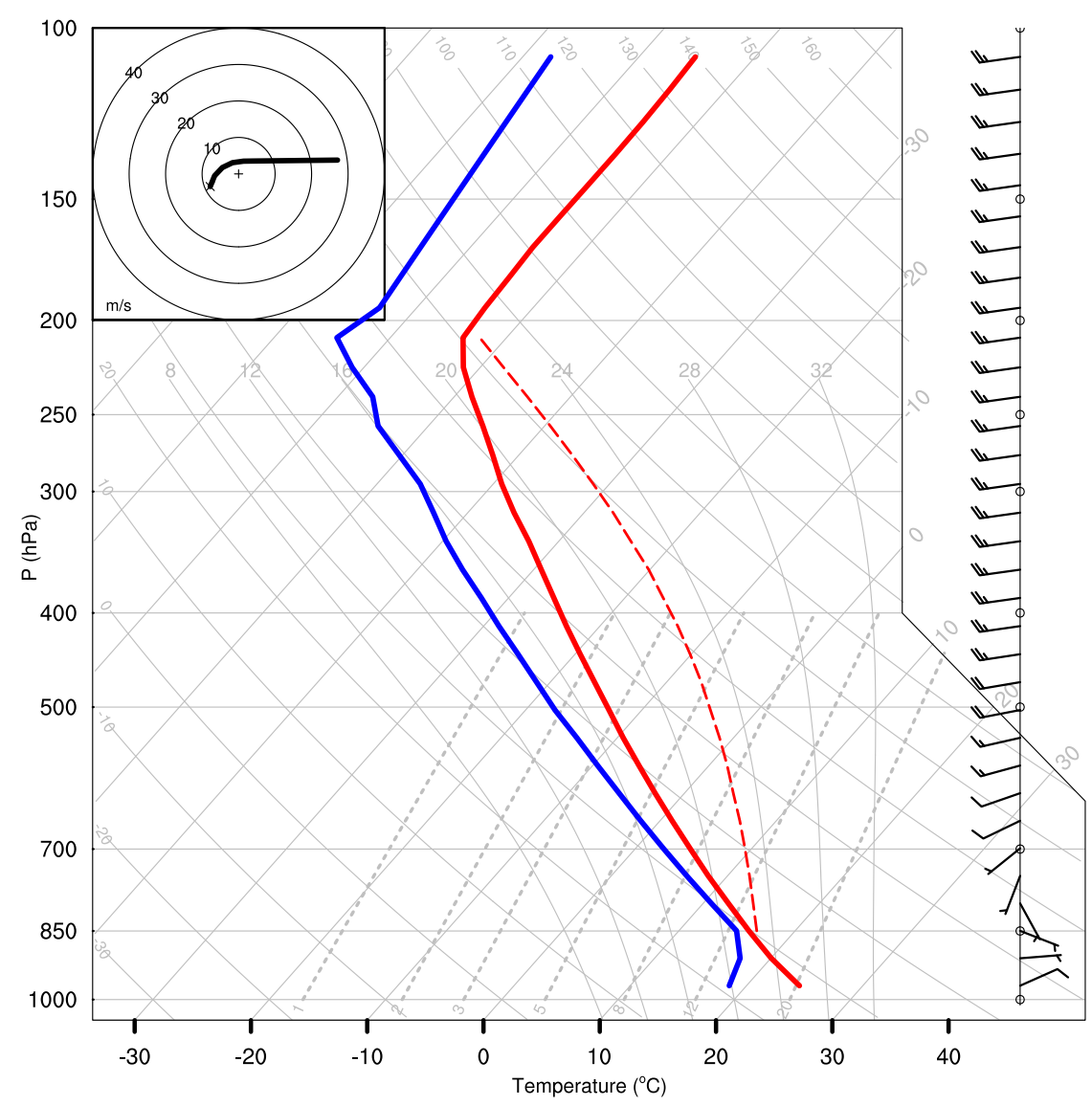

FIG. 1. Initial environmental hodograph and sounding of the nature run.

are somewhat consistent with "worst-case scenario" estimates of data quality for a rapid-scan phased-array radar, where data quality for radial velocity estimates are assessed using Eq. (2) from Yu et al. (2007). The variance of the mean velocity estimator ( $\mathrm{Yu}$ et al. 2007) is

$$
\operatorname{var}\left\{\hat{\boldsymbol{v}}_{C}\right\}=\frac{K}{M-1}\left\{\left[1-\rho^{2}\left(T_{s}\right)\right] \sum_{l=-(M-2)}^{M-2} \frac{M-1-|l|}{M-1} \rho^{2}\left(l T_{s}\right)+\frac{1}{\mathrm{SNR}^{2}}+\frac{1}{\mathrm{SNR}}\left[1-\frac{M-2}{M-1} \rho\left(2 T_{s}\right)\right]\right\}
$$

where $\hat{v}_{C}$ is estimator of mean velocity; $M$ is the sample number; SNR is the signal-to-noise ratio; $K=\lambda^{2} /\left[32 \pi^{2} T_{s}^{2} \rho^{2}\left(T_{s}\right)\right]$, where $\lambda$ is the radar wavelength; $\rho\left(l T_{s}\right)$ is the correlation coefficient of weather signals; and $T_{s}$ is pulse repetition time (PRT). For error estimates, the primary factors are spectrum width, the number of pulses per radial, and the SNR. Assuming a spectrum width of $\sim 5.25 \mathrm{~m} \mathrm{~s}^{-1}$, a speedup factor of 2.5 relative to NEXRAD (i.e., a 2.5 -fold reduction in the number of pulses per radial), and an $\sim 2$-ms PRT, the expected standard deviation of radial velocity is $2.2 \mathrm{~m} \mathrm{~s}^{-1}$ for a high SNR case and $3.5 \mathrm{~m} \mathrm{~s}^{-1}$ for a relatively low SNR of $2 \mathrm{~dB}$. Thus, using 2 and $4 \mathrm{~m} \mathrm{~s}^{-1}$ for the errors in the precipitation and clear-air regions, respectively, is likely a reasonable assumption for the "worst case scenario" data quality. However, it should be noted that the exact scan parameters (PRT, speedup factor required, noise floor, etc.) are dependent on the final radar design and requirements. A similar observation error standard deviation of $4 \mathrm{~m} \mathrm{~s}^{-1}$ is used as an upper bound for clearair radial velocity observations by $\mathrm{Lu}$ and $\mathrm{Xu}$ (2009).

\section{b. Experiment design}

The assimilation experiments are conducted using a 50-member ensemble with a perfect-model assumption. Initially, each member is created by perturbing the wind fields of the homogeneous environment sounding with a standard deviation of $4 \mathrm{~m} \mathrm{~s}^{-1}$ from the surface to $11 \mathrm{~km}$ 

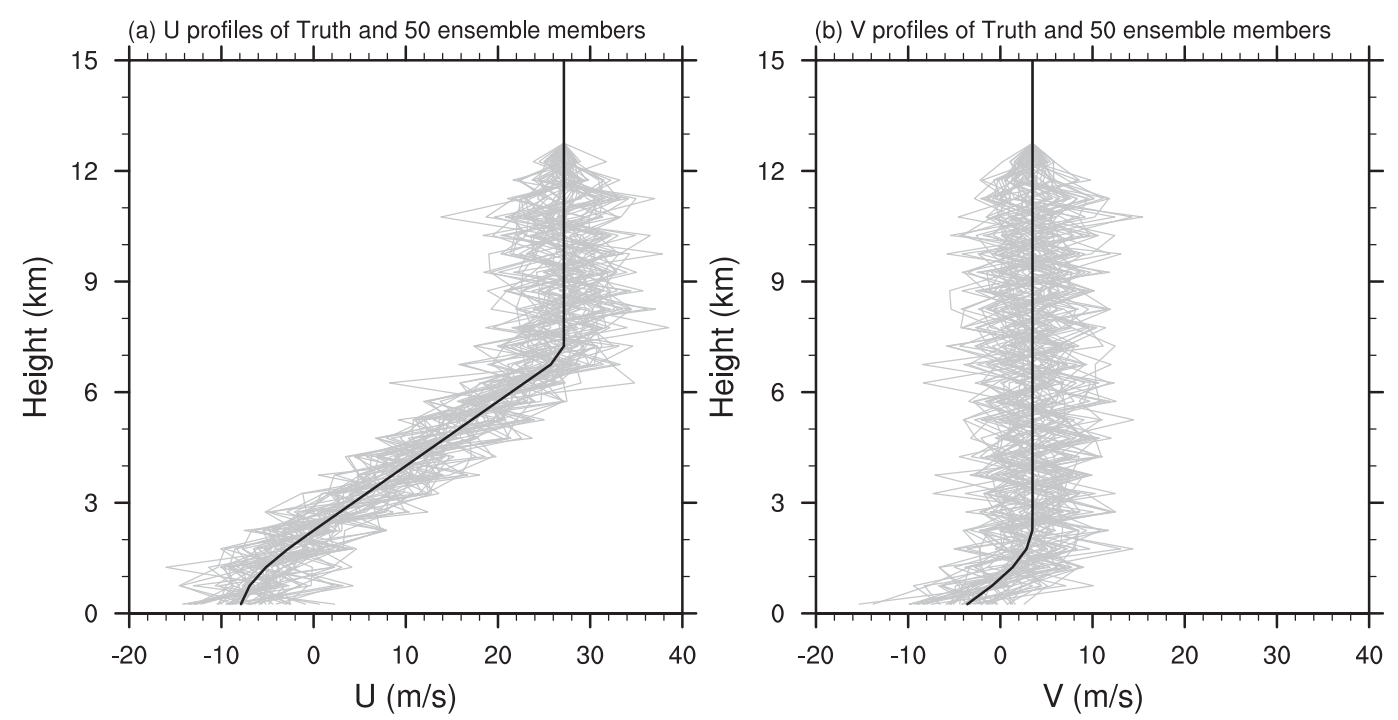

FIG. 2. The (a) $u$ and (b) $v$ vertical wind profiles of the truth simulation (black thick line) and 50 ensemble members (gray thin lines).

and linearly transitioning to $0 \mathrm{~m} \mathrm{~s}^{-1}$ at $13 \mathrm{~km}$ (Dowell et al. 2004). The standard deviation of $4 \mathrm{~m} \mathrm{~s}^{-1}$ is roughly consistent with the magnitude of root-mean-square errors of vector wind magnitude for Rapid Refresh-Earth System Research Laboratory (RAP-ESRL) and Rapid Update Cycle (RUC) 6-h forecasts, verified against rawinsonde observations over the contiguous United States (Benjamin et al. 2016). Note that in this study all data assimilation (DA) experiments use the same set of perturbations supplied to the ensemble environments. The wind profiles of the truth simulation and ensemble members are shown in Fig. 2.

The data assimilation method adopted in this study is the ensemble adjustment Kalman filter (Anderson 2001) from the Data Assimilation Research Testbed (DART; http://www.image.ucar.edu/DAReS/DART; Anderson et al. 2009). The data assimilation parameters used in this study are similar to those in Kerr et al. (2015). Horizontal and vertical covariance localizations (Gaspari and Cohn 1999) with a 12-km cutoff radius are applied to PAR observations. Additive noise is inserted where radar reflectivity observations are greater than $25 \mathrm{dBZ}$ (Dowell and Wicker 2009; Sobash and Wicker 2015). It should be noted that the localization scales in precipitating and environmental regions are the same in this study. The localization parameters for the environmental data assimilation are not tuned and additional tuning to optimize the parameter of assimilating the clear-air data should be considered in future studies.

Previous studies (e.g., Nowotarski and Markowski 2016; Limpert and Houston 2018; Kerr et al. 2019) indicated that supercell thunderstorms can induce substantial environmental perturbations, which may in turn affect the strength and structure of the storm. The feedback between the storm and its environment can be sensitive to the strength of the storm. Therefore, data assimilation experiments are conducted in different stages of the storm to investigate this sensitivity. The assimilation experiments start at $t=30,45,60,75$, and $90 \mathrm{~min}$, respectively. The data assimilation is conducted with 1-min cycling for a total of $5 \mathrm{~min}$, followed by forecasts out to $t=185 \mathrm{~min}$. Because the idealized supercell simulated in this study develops and matures quickly, a 5 -min-wide assimilation window is selected.

There are three groups of assimilation experiments. All three experiment groups assimilate radar reflectivity observations (including clear air) every $1 \mathrm{~min}$. The assimilation of clear-air reflectivity helps to suppress spurious convection around the main storm (Tong and Xue 2005; Jones et al. 2015). The radar reflectivity is assimilated directly as a state variable in DART (Jones and Wicker 2014, 2015). In this study, we mainly want to investigate the added value of assimilating clear-air radial velocity observations on the forecasting of supercell thunderstorm. In addition to assimilating reflectivity observations, the first group of experiments (hereinafter EXP1) assimilates radial velocity observations only in the precipitating region (observed reflectivity $>10 \mathrm{dBZ}$ ) using 1-min cycles. The second group of experiments (hereinafter EXP2) is the same as EXP1, except that clear-air radial velocity observations are also assimilated every $5 \mathrm{~min}$ to investigate the impact of assimilating clear-air radial velocity observations. The third group of experiments (hereinafter EXP3) is the same as EXP2, 
except that clear-air radial velocity observations are assimilated every $1 \mathrm{~min}$ to investigate the impact of assimilating high-time-frequency clear-air radial velocity observations.

The timelines for all experiments with data assimilation are shown in Fig. 3. The ensemble run without data assimilation is marked as CTRL for comparison. The observation-space root-mean-square innovation (RMSI) and total ensemble spread (standard deviation) for assimilated radial velocity observations in precipitating and clear-air regions are compared. In general, the ensemble is underdispersive for precipitation region with a consistency ratio (Dowell et al. 2004) of $\sim 0.84$ and overdispersive for the clear-air region with a consistency ratio of $\sim 1.12$. Though the consistency ratios deviate from the perfect value of 1 , the consistency ratios in this study are within acceptable ranges for similar radar DA studies (e.g., Dowell et al. 2004; Dowell and Wicker 2009; Yussouf et al. 2013).

\section{Results}

\section{a. Forecast skill score of reflectivity forecasts}

The fractions skill score (FSS), a neighborhood verification method (Roberts and Lean 2008), is adopted to evaluate the forecast skill of ensemble forecasts from all four experiments. The expression of FSS is

$$
\mathrm{FSS}=1-\frac{\frac{1}{N} \sum_{i=1}^{N}\left(P_{f}-P_{o}\right)^{2}}{\frac{1}{N} \sum_{i=1}^{N} P_{f}^{2}+\frac{1}{N} \sum_{i=1}^{N} P_{o}^{2}},
$$

where $P_{f}$ and $P_{o}$ are the forecast and observed fraction of each neighborhood grid box, respectively, and $N$ is the number of grid points in the examined domain. FSS values range from 0 to 1 . An FSS of 0 means that the forecast has no skill, whereas an FSS of 1 means the forecast is perfect. The FSS has been widely used for the evaluation of high-resolution precipitation forecasts (e.g., Mittermaier and Roberts 2010; Johnson and Wang 2016; Coniglio et al. 2016; Huang et al. 2018). Figure 4 shows the ensemble mean FSS in different experiments for a composite reflectivity threshold of $40 \mathrm{~dB} Z$ for a box with a width of $8 \Delta(16 \mathrm{~km} \times 16 \mathrm{~km}$; Coniglio et al. 2016). This box size of $8 \Delta$ is selected mainly to reduce the influence of errors associated with spatial scales close to or smaller than the smallest resolvable scales of the model grid ( $\sim 4-6 \Delta$ or less; Skamarock 2004). Statistically significant FSS differences (at the 0.05 significance level) of EXP2 and EXP3 over EXP1 are judged by a $t$ test with the assumption that the ensemble

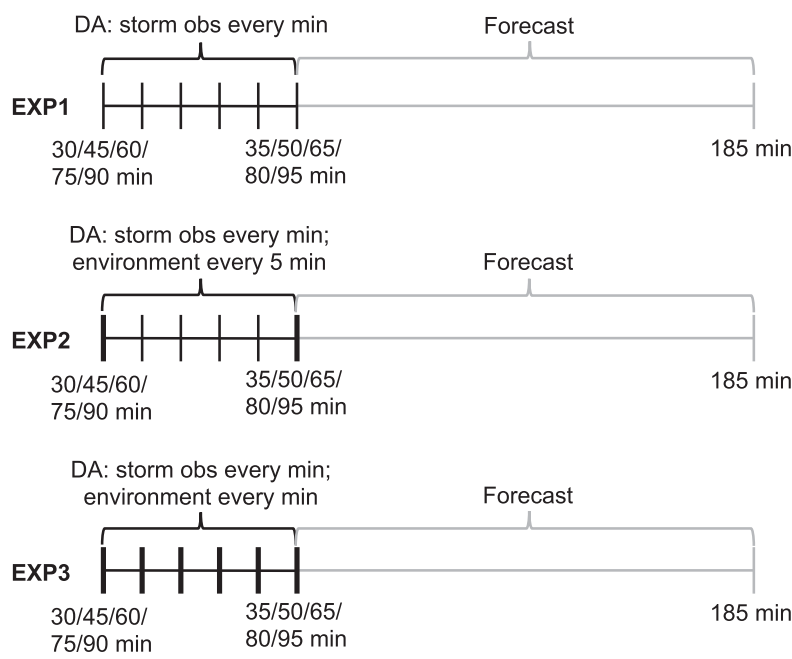

FIG. 3. Timelines of the experiments EXP1, EXP2, and EXP3 showing data assimilation (DA) from $t=30,45,60,75$, and $90 \mathrm{~min}$ to $t=35,50,65,80$, and 95 (5-min DA period), respectively. The model forecasts from the end of the DA windows to $t=185 \mathrm{~min}$.

members in each run serve as independent samples (Hamill 1999).

As shown in Fig. 4, all the experiments with data assimilation (EXP1, EXP2, and EXP3) have much better forecast skills than the experiment without data assimilation (CTRL) for all forecast times. For the forecast after $\sim 30 \mathrm{~min}$, the experiments assimilating clear-air radial velocity observation (EXP2 and EXP3) generally have better forecast skills than the experiment without assimilation of clear-air radial velocity (EXP1). This positive impact persists for all stages of the supercell's life cycle. As shown in Fig. 4 , it takes $\sim 30$ min for the ensemble forecast to realize the benefits of assimilating clear-air radial velocity observations. This result supports the hypothesis that increasing the accuracy of environmental wind fields through assimilating clear-air radial velocity can improve the prediction of a supercell by capturing the interaction between the storm and the environment.

Examining the two clear-air assimilation experiments with different assimilation frequencies, the difference of FSSs between EXP2 and EXP3 is small across different forecast times (Fig. 4), which may be due to the relatively slow change of the environmental winds compared to the precipitation region during the 5-min period. It should be noted that the slower evolving environmental winds might be associated with prescribed homogeneous background winds in this idealized case study. From forecasts started during the early stage of storm (Fig. 4, top-left panel), EXP2 has a slightly higher FSS than EXP3 after forecast times of $120 \mathrm{~min}$, while FSS is slightly higher for EXP3 compared to EXP2 for 

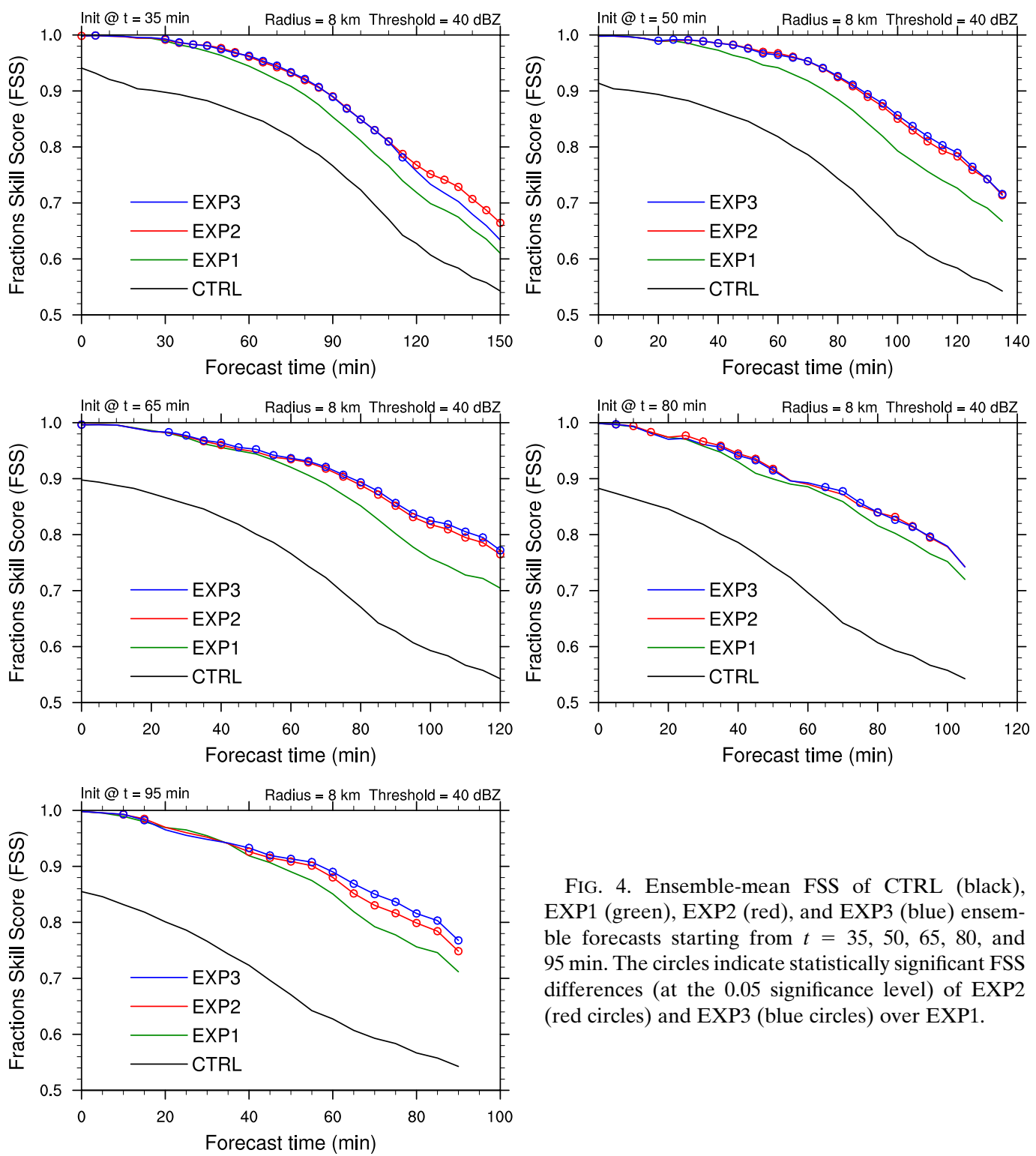

FIG. 4. Ensemble-mean FSS of CTRL (black), EXP1 (green), EXP2 (red), and EXP3 (blue) ensemble forecasts starting from $t=35,50,65,80$, and $95 \mathrm{~min}$. The circles indicate statistically significant FSS differences (at the 0.05 significance level) of EXP2 (red circles) and EXP3 (blue circles) over EXP1.

forecasts started during the later stage of storm (Fig. 4, bottom panel). The FSSs between EXP2 and EXP3 are similar when forecasts started during the middle stage of storm (top-right and middle panels of Fig. 4).

\section{b. Wind field errors}

To diagnose the benefits of assimilating clear-air radial velocity observations, each experiment covering five different stages of the storm is examined. It was found that these experiments at different stages produce similar results. Therefore, the experiment in which the assimilation period is $t=60-65 \mathrm{~min}$ and ensemble forecasts start from $t=65$ to $185 \mathrm{~min}$ is used as an example here. The wind vector errors at both the

analysis and 60-min forecast are first calculated to examine the improvement in the wind fields. The ensemble mean wind vector errors are calculated using $(1 / 50) \sum_{m=1}^{50}\left|\mathbf{V}_{m}-\mathbf{V}_{\text {Truth }}\right|$, where $\mathbf{V}_{m}$ is the horizontal wind vector of the $m$ th ensemble member, and $\mathbf{V}_{\text {Truth }}$ is the horizontal wind vector from the truth simulation.

The ensemble mean horizontal wind vector errors at 1- and 3-km height at the analysis and the 60-min forecast lead times are displayed in Fig. 5. Relative to CTRL, assimilating radial velocity in the precipitation region only (EXP1) significantly reduces the wind error in the analysis within the storm and near-storm environment ( $\sim 20 \mathrm{~km}$ from the precipitating region). Such an improvement is carried out to the 60 -min lead time and the 

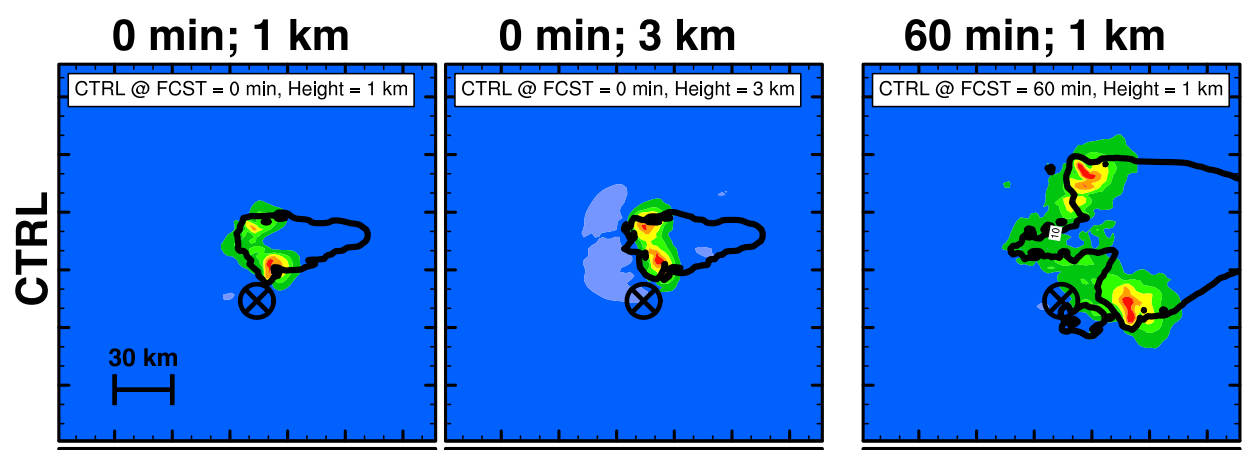

\section{$60 \mathrm{~min} ; 3 \mathrm{~km}$}
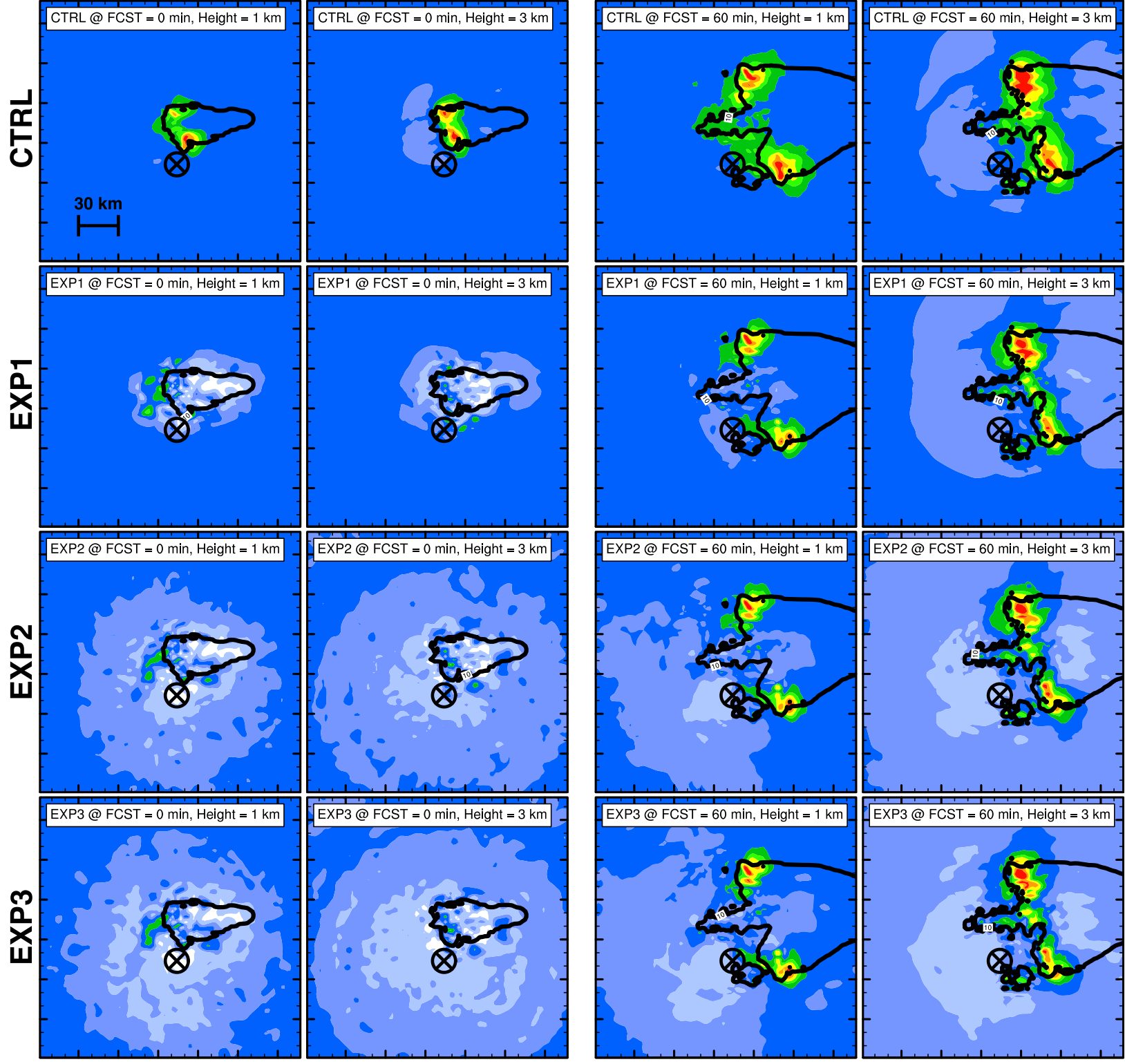

[Mean UV Error: $\mathrm{m} \mathrm{s}^{-1}$ ]

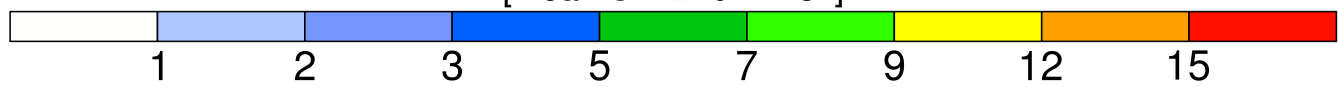

FIG. 5. Ensemble mean (left),(right center) 1- and (left center),(right) 3-km horizontal wind vector errors (shaded; $\mathrm{m} \mathrm{s}^{-1}$ ) of the (top) CTRL, (top middle) EXP1, (bottom middle) EXP2, and (bottom) EXP3 ensemble forecasts at 0- and 60-min forecasts starting from $t=$ $65 \mathrm{~min}$. The black contours represent the $10-\mathrm{dB} Z$ radar reflectivity factor of the truth simulation. The $\mathrm{x}$-filled circles indicate the radar location. Minor tick marks are included every $10 \mathrm{~km}$, and major tick marks are included every $30 \mathrm{~km}$.

area of improvement is slightly expanded during the forecast. Relative to EXP1, the area of environmental wind error reduction is expanded significantly in both the analysis and the 60-min forecast in EXP2 and EXP3 after clear-air radial velocity observations are assimilated. Though wind errors within strong updraft regions are similar among EXP1, EXP2 and EXP3, it is also noted that the wind errors in the remaining part of precipitation region are smaller in EXP2 and EXP3 than those in EXP1 in the 60-min forecast. This result indicates that the increasing accuracy of environment wind fields through assimilating clear-air radial velocity can 

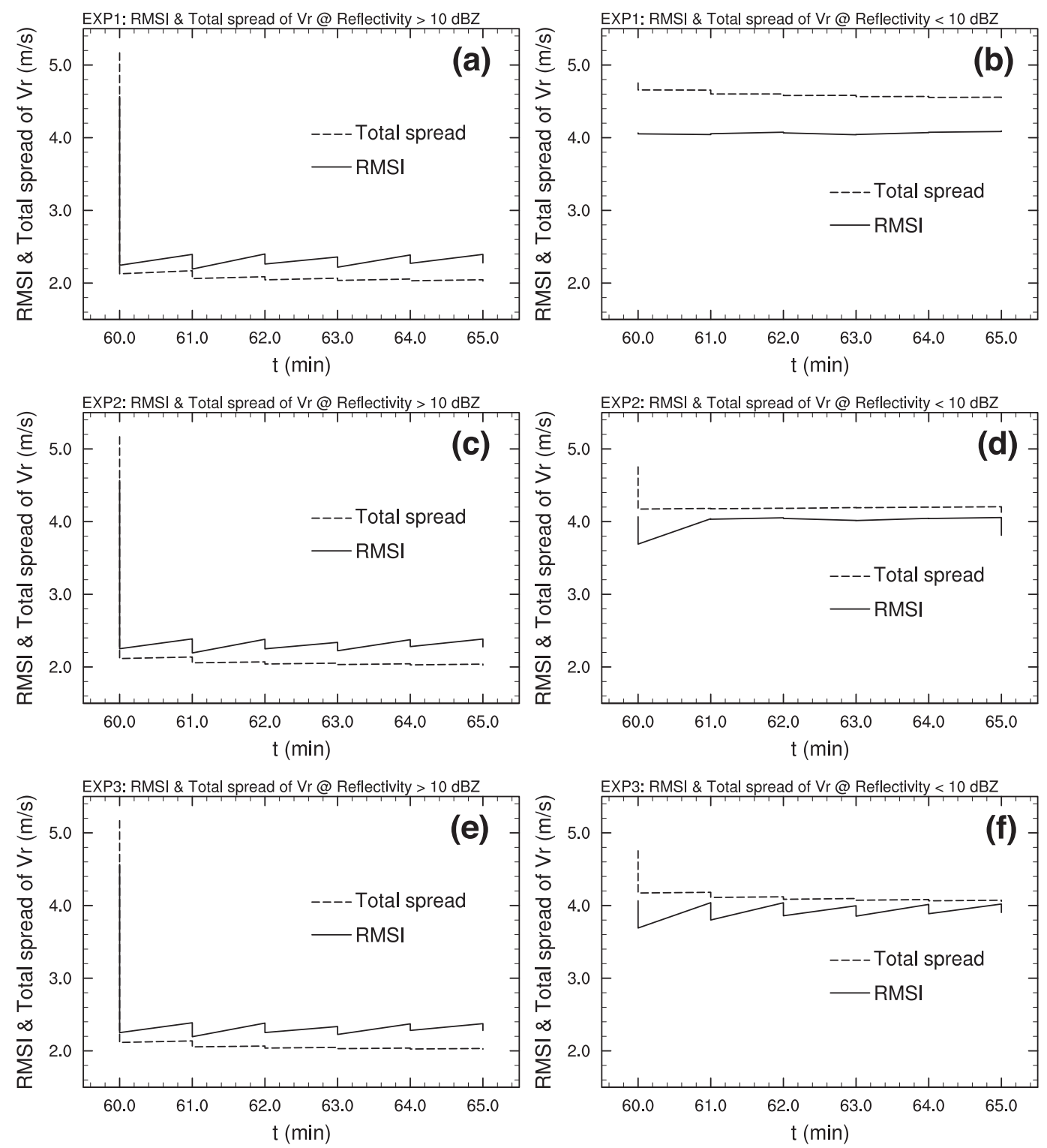

FIG. 6. Observation-space RMSI and total ensemble spread (standard deviation) for assimilated radial velocity observations in (left) precipitation regions (reflectivity $>10 \mathrm{dBZ}$ ) and (right) clear-air regions (reflectivity $<$ $10 \mathrm{dBZ}$ ) for (a),(b) EXP1, (c),(d) EXP2, and (e),(f) EXP3 during the 5-min data assimilation period from $t=60$ to $65 \mathrm{~min}$.

also improve the accuracy of the winds within the precipitation region by capturing the interaction between storm and environment. Consistent with the left-middle panel of Fig. 4, the wind errors in the precipitation and near-storm regions are slightly more accurate in EXP3 than EXP2.

The improved near-storm environment wind analysis shown in Fig. 5 is also reflected in the sawtooth plot (Fig. 6). As shown in Fig. 6, the primary differences in observation-space RMSI and total spread among the three experiments are observed in clear-air regions. The
RMSI for assimilated radial velocity observations in clear-air regions in EXP2 and EXP3 are similar and both smaller than that in EXP1 at the end of assimilation period $(t=65$ min; Fig. 6).

\section{c. Probabilistic forecasts of updraft helicity and precipitation}

The 2-5-km updraft helicity (UH) is commonly used as a parameter to identify rotating updrafts in the lower to middle troposphere (Kain et al. 2008). The UH probabilistic forecasts derived from an ensemble are a 
useful surrogate to forecast the path of severe weather, such as the paths of mesocyclone and tornado (Clark et al. 2013; Cintineo and Stensrud 2013). The UH is calculated by the product of vertical velocity and vertical vorticity integrated between 2 and $5 \mathrm{~km}$ above ground level. It is given by

$$
\mathrm{UH}=\int_{z_{1}}^{z_{2}} w \zeta d z,
$$

where $z_{1}=2000 \mathrm{~m}$ and $z_{2}=5000 \mathrm{~m}, w$ is the vertical velocity, and $\zeta=(\partial v / \partial x)-(\partial u / \partial y)$ is the vertical vorticity. Right-moving storms are preferred in the quartercircle (low-level clockwise) hodograph sounding used in this study (Markowski and Richardson 2010). To investigate the forecast skill of the track of right-moving storm, the probability swath of the maximum positive gridpoint $\mathrm{UH}$ associated with the right-moving storm is examined. The maximum positive $\mathrm{UH}$ here means the temporal-maximum value of $\mathrm{UH}$ at each model grid point within the examined period (Kain et al. 2010).

The probability of temporal-maximum $\mathrm{UH} \geq 200 \mathrm{~m}^{2} \mathrm{~s}^{-2}$ in the ensemble forecasts CTRL, EXP1, EXP2 and EXP3 starting from $t=65$ to $185 \mathrm{~min}$ is shown in Fig. 7 . Compared to CTRL (Fig. 7a), the probability in EXP1 (Fig. 7b) increases significantly within the swaths of temporal-maximum $\mathrm{UH} \geq 200 \mathrm{~m}^{2} \mathrm{~s}^{-2}$ of the truth simulation after assimilating the radar data in precipitation regions. With the addition of environmental clear-air radial velocity assimilated in EXP2 and EXP3, probabilities increase again within the truth UH swaths and the probabilities decrease outside the truth UH swaths (Figs. 7c-f). This increase of the probability within the truth UH swaths after assimilating clear-air observations can exceed $30 \%$, and the decrease of the probability outside the truth UH swaths after assimilating clear-air observations can exceed $20 \%$ (Figs. 7e,f).

The probability swath of accumulated precipitation associated with right-moving storms is also examined. Figure 8 shows probability of the 2-h (from $t=65$ to $185 \mathrm{~min}$ ) accumulated precipitation $\geq 40 \mathrm{~mm}$ in the ensemble forecasts from CTRL, EXP1, EXP2, and EXP3. Compared to the probability distribution of $\mathrm{UH}$, the probability distribution of accumulated precipitation has similar characteristics. After assimilating the environmental clear-air radial velocity in EXP2 and EXP3, the probabilities within the truth precipitation swath can be increased by more than $40 \%$ relative to EXP1 (Figs. 8e,f). Meanwhile, it is noted that the probability is increased in the latter half of the swath. Specifically, probability greater than $40 \%$ in EXP2 (Fig. 8c) and greater than $50 \%$ in EXP3 (Fig. 8d) approaches the end of the truth precipitation swath. In comparison, probability greater than $40 \%$ spans only up to one-half of the truth precipitation swath in EXP1 (Fig. 8b). Such an improvement of both the $\mathrm{UH}$ and precipitation probability swath forecasts in EXP2 and EXP3 not only reflects that the improved forecast track of supercell, but the simulated storm itself is better maintained over a longer duration.

\section{d. Dynamical diagnostics on the impact of assimilating clear-air observations}

To further provide dynamical understanding of the impact of assimilating environmental clear-air radial velocity on the subsequent prediction of storm track and maintenance, member 7 of the ensemble forecasts (a member representing the ensemble forecast performance through examining the $\mathrm{UH}$ and precipitation forecasts of each member) from CTRL, EXP1, EXP2, and EXP3 starting from $t=65$ to $185 \mathrm{~min}$ is selected.

Figures 9 and 10 show the temporal-maximum gridpoint $\mathrm{UH}$ and 2-h accumulated precipitation, respectively, for the right-moving storm from the truth simulation and member 7 of CTRL, EXP1, EXP2, and EXP3 between $t=65$ and $185 \mathrm{~min}$. In comparing Figs. 9 and 10 with Figs. 7 and 8, it is seen that member 7 is representative of the ensemble forecast performance. Relative to the truth simulation (Figs. 9a and 10a), there are large displacement errors $(\sim 25 \mathrm{~km})$ in CTRL without assimilating any radar data (Figs. $9 \mathrm{~b}$ and 10b). The displacement errors are reduced significantly in the experiments assimilating radar data only in the precipitation region (EXP1). In other words, assimilating radar observations in the precipitation region is still more important than assimilating data in clear-air regions. In this study, we mainly want to investigate the added value of assimilating clear-air radial velocity observations on the forecasting of supercell thunderstorm, in addition to assimilating radar data within the precipitation region. Briefly, after assimilating the environment clear-air radial velocity observations, the UH values and paths in EXP2 and EXP3 more closely resemble those of the truth than those in EXP1 (Fig. 9). The accumulated precipitation forecasts in EXP2 and EXP3 are consistent with that of the truth simulation in terms of both the distribution (path direction and length) and intensity, while the precipitation intensity in EXP1 is not maintained well in the later stage (Fig. 10). Therefore, improving the forecast near-storm environmental winds through assimilating clear-air radial velocity can improve the accuracy of forecast storm structure (rotating updrafts), duration, and accumulated precipitation.

To further investigate the impact of assimilating clearair radial velocity on the subsequent simulation of the supercell's dynamic structure and its maintenance and 


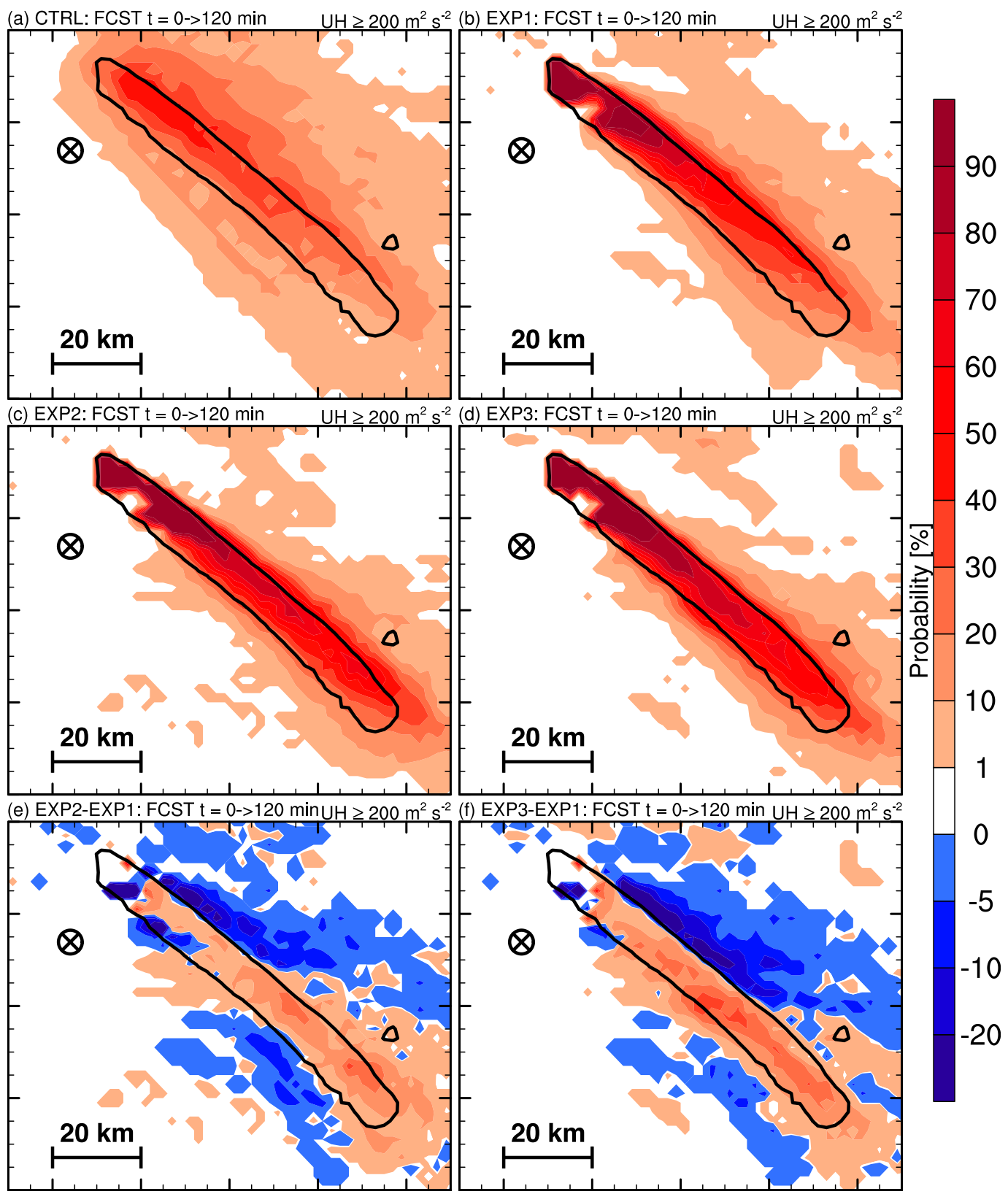

FIG. 7. Probability (shaded; \%) of temporal-maximum 2-5-km updraft helicity (UH) $\geq 200 \mathrm{~m}^{2} \mathrm{~s}^{-2}$ for the rightmoving storm in the ensemble forecasts (a) CTRL, (b) EXP1, (c) EXP2, and (d) EXP3 starting from $t=65$ to $185 \mathrm{~min}$ (forecast period 0-120 min). Also shown are the probability differences (e) between EXP2 and EXP1 and (f) between EXP3 and EXP1. The black contours represent the temporal-maximum gridpoint $\mathrm{UH}=200 \mathrm{~m}^{2} \mathrm{~s}^{-2}$ from $t=65$ to $185 \mathrm{~min}$ of the truth simulation. The $\mathrm{x}$-filled circles indicate the radar location. Minor tick marks are included every $5 \mathrm{~km}$, and major tick marks are included every $20 \mathrm{~km}$.

propagation, the distributions of temporal-height-maximum gridpoint vertical velocity in truth simulation as well as forecasts of member 7 from CTRL, EXP1, EXP2 and EXP3 during the period $t=65-185 \mathrm{~min}$ are also shown in Fig. 10. In the truth simulation, the strong updrafts $\left(w>25 \mathrm{~m} \mathrm{~s}^{-1}\right)$ are maintained along the path of the heavy surface precipitation $(\geq 40 \mathrm{~mm})$ to the end of the examined period ( $t=185 \mathrm{~min}$, Fig. 10a). However, in EXP1, the strong updrafts $\left(w>25 \mathrm{~m} \mathrm{~s}^{-1}\right)$ are smaller, especially near the end of the examined period, resulting in less surface precipitation (Fig. 10c). In the experiments also assimilating environmental clear-air radial velocity (EXP2 and EXP3), the sizes of strong updrafts $\left(w>25 \mathrm{~m} \mathrm{~s}^{-1}\right)$, especially in EXP2, more closely match 


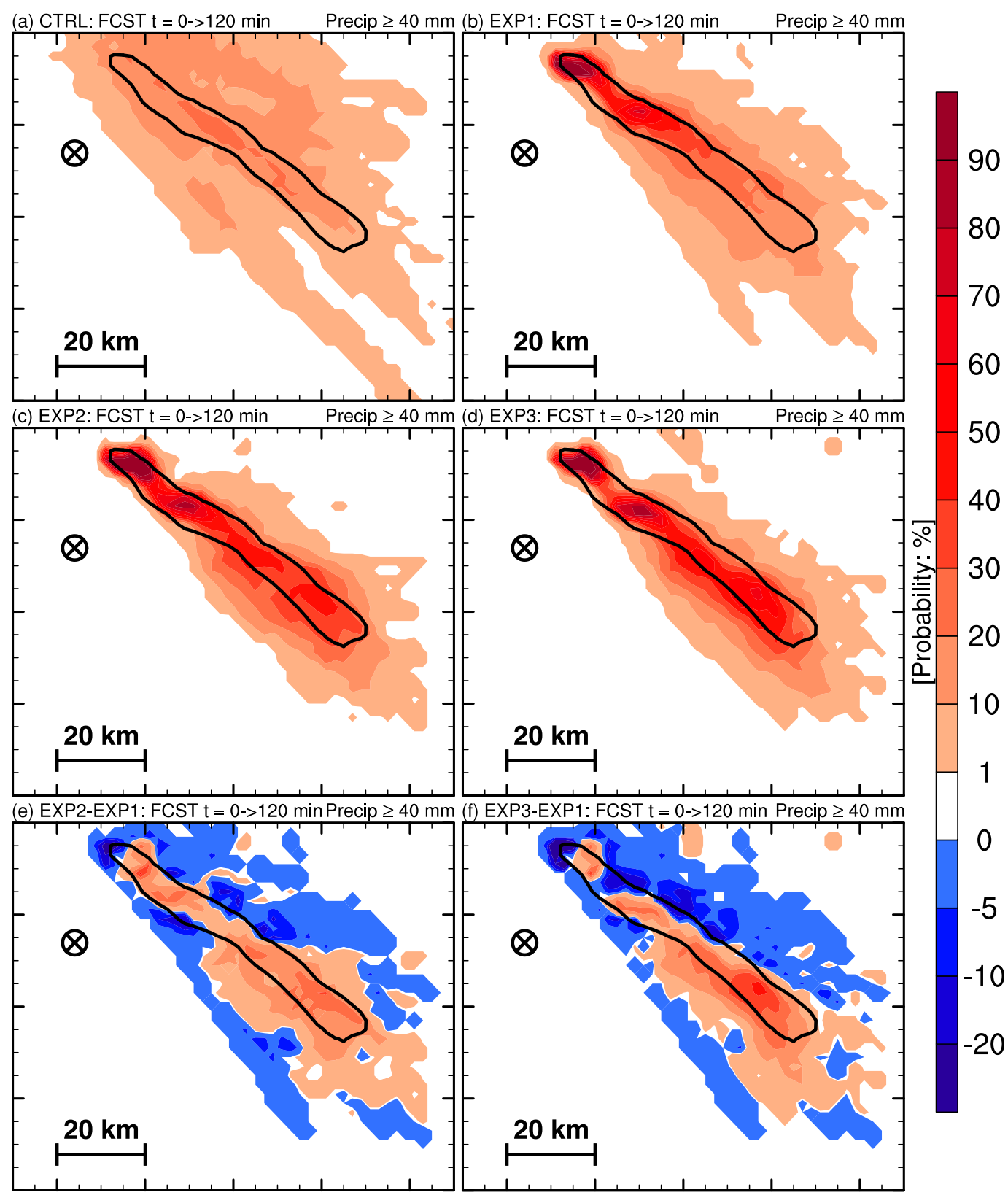

FIG. 8. As in Fig. 7, but of 2-h accumulated precipitation $\geq 40 \mathrm{~mm}$. The black contours represent the $40-\mathrm{mm}$ accumulated precipitation of the truth simulation.

the truth simulation. The strong updrafts $\left(w>25 \mathrm{~m} \mathrm{~s}^{-1}\right)$ in EXP2 and EXP3 are also maintained throughout the forecast period, resulting in the similar intensity of surface precipitation as the truth (Figs. 10d,e).

Figure 11 shows the horizontal wind vectors, $3-\mathrm{km}$ radar reflectivity, and hodographs of truth simulation as well as member 7 of CTRL, EXP1, EXP2, and EXP3. Compared to CTRL, the storm structures in EXP1, EXP2, and EXP3 more closely resemble the truth simulation after assimilating radar data. The near-storm inflow environmental winds shown within black boxes in EXP2 and EXP3 are more similar to truth than EXP1 (Fig. 11), indicating assimilating clear-air radial velocity can correct environmental wind fields. This benefit can be seen obviously from the hodographs in Fig. 11f. The hodographs in EXP2 and EXP3 are closer to the truth than those in CTRL and EXP1, especially in the lower levels (Fig. 11f). Therefore, assimilating clear-air radial velocity corrects the near-storm environmental wind profiles and environmental wind shear. 


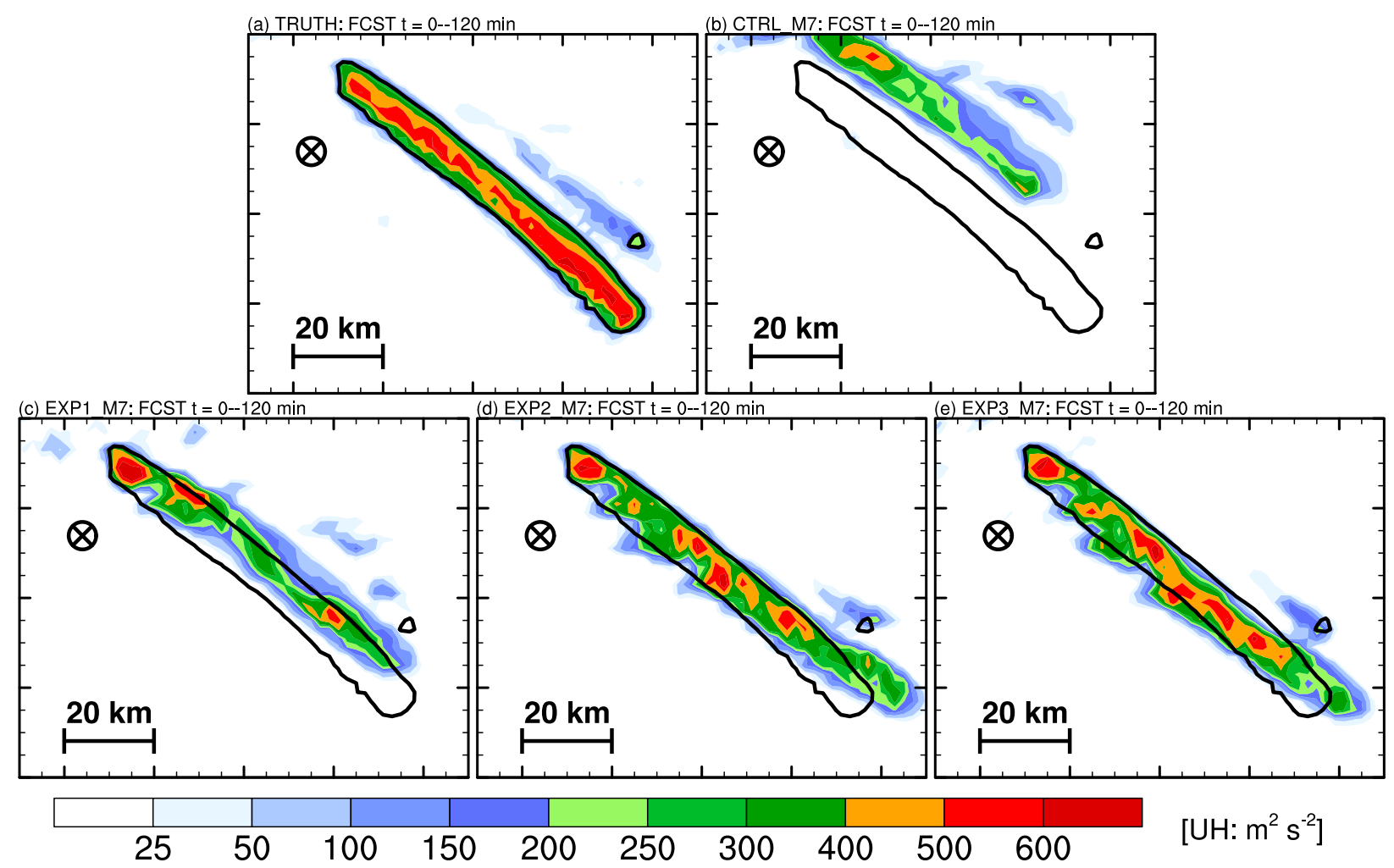

FIG. 9. Temporal-maximum 2-5 km updraft helicity (UH, shaded, $\mathrm{m}^{2} \mathrm{~s}^{-2}$ ) for the right-moving storm of (a) the truth simulation and the member-7 forecast of (b) CTRL, (c) EXP1, (d) EXP2, and (e) EXP3 starting from $t=65$ to 185 min (forecast period 0-120 min). The black contours represent the temporal-maximum gridpoint $\mathrm{UH}=200 \mathrm{~m}^{2} \mathrm{~s}^{-2}$ from $t=65$ to $185 \mathrm{~min}$ of truth simulation. The $\mathrm{x}$-filled circles indicate the radar location. Minor tick marks are included every $5 \mathrm{~km}$, and major tick marks are included every $20 \mathrm{~km}$.

To investigate the benefits of assimilating clear-air radial velocity to the dynamics that give rise to vertical acceleration and affect supercell propagation, the dynamic vertical perturbation pressure gradient force (VPPGF) is examined. As shown in Markowski and Richardson (2010), in strongly rotating updrafts of a supercell, the fluid extension terms do not contribute to the dynamic VPPGF as much as the $\zeta^{\prime 2}$ and $\mathbf{S} \cdot \nabla_{h} w^{\prime}$ terms. Therefore, the dynamic VPPGF can be parsed as follows:

$$
-\frac{\partial p_{D}^{\prime}}{\partial z} \propto \underbrace{\frac{1}{2} \frac{\partial \zeta^{\prime 2}}{\partial z}}_{\text {Nonlinear dynamic forcing Linear dynamic forcing }} \underbrace{-2 \frac{\partial}{\partial z} \mathbf{S} \cdot \nabla_{h} w^{\prime}}
$$

where $p_{D}^{\prime}$ is dynamic perturbation pressure, $\zeta^{\prime}$ is vertical vorticity perturbation, $\nabla_{h} w^{\prime}=\left(\partial w^{\prime} / \partial x, \partial w^{\prime} / \partial y\right)$ is the horizontal gradient of the vertical velocity perturbation, and $\mathbf{S}=\left(\partial u_{0} / \partial z, \partial v_{0} / \partial z\right)$ is vertical environmental wind shear. When the terms on the right-hand side (rhs) of Eq. (4) are positive or negative, the contribution to the vertical acceleration is respectively upward or downward. The nonlinear dynamic forcing term [the first term on the rhs of Eq. (4)] is associated with rotation (cyclonic or anticyclonic). The linear dynamic forcing term [the second term on the rhs of Eq. (4)]) is associated with the interaction between an updraft and the environmental vertical wind shear.

To calculate the linear and nonlinear dynamic VPPGF terms, we first diagnose $p_{D}^{\prime}$, and its linear component $p_{\mathrm{DL}}^{\prime}$ numerically. Following previous studies (Rotunno and Klemp 1982; Weisman and Rotunno 2000; Parker and Johnson 2004; Huang et al. 2019), based on the absence of friction and the anelastic approximation, the diagnostic dynamic perturbation pressure equation is given by

$$
\begin{aligned}
\nabla^{2} p_{D}^{\prime}= & -\rho_{0}\left[\left(\frac{\partial u}{\partial x}\right)^{2}+\left(\frac{\partial v}{\partial y}\right)^{2}+\left(\frac{\partial w}{\partial z}\right)^{2}-w^{2} \frac{\partial^{2}}{\partial z^{2}}\left(\ln \rho_{0}\right)\right] \\
& -2 \rho_{0}\left(\frac{\partial v}{\partial x} \frac{\partial u}{\partial y}+\frac{\partial u}{\partial z} \frac{\partial w}{\partial x}+\frac{\partial v}{\partial z} \frac{\partial w}{\partial y}\right)
\end{aligned}
$$

where $\rho_{0}$ is the base state of air density. Further, the velocities are separated into mean and perturbation components (i.e., $u=u_{0}+u^{\prime}, v=v_{0}+v^{\prime}$, and $w=w^{\prime}$ ), and the linear component $\left(p_{\mathrm{DL}}^{\prime}\right)$ of the dynamic perturbation pressure equation can be given by 


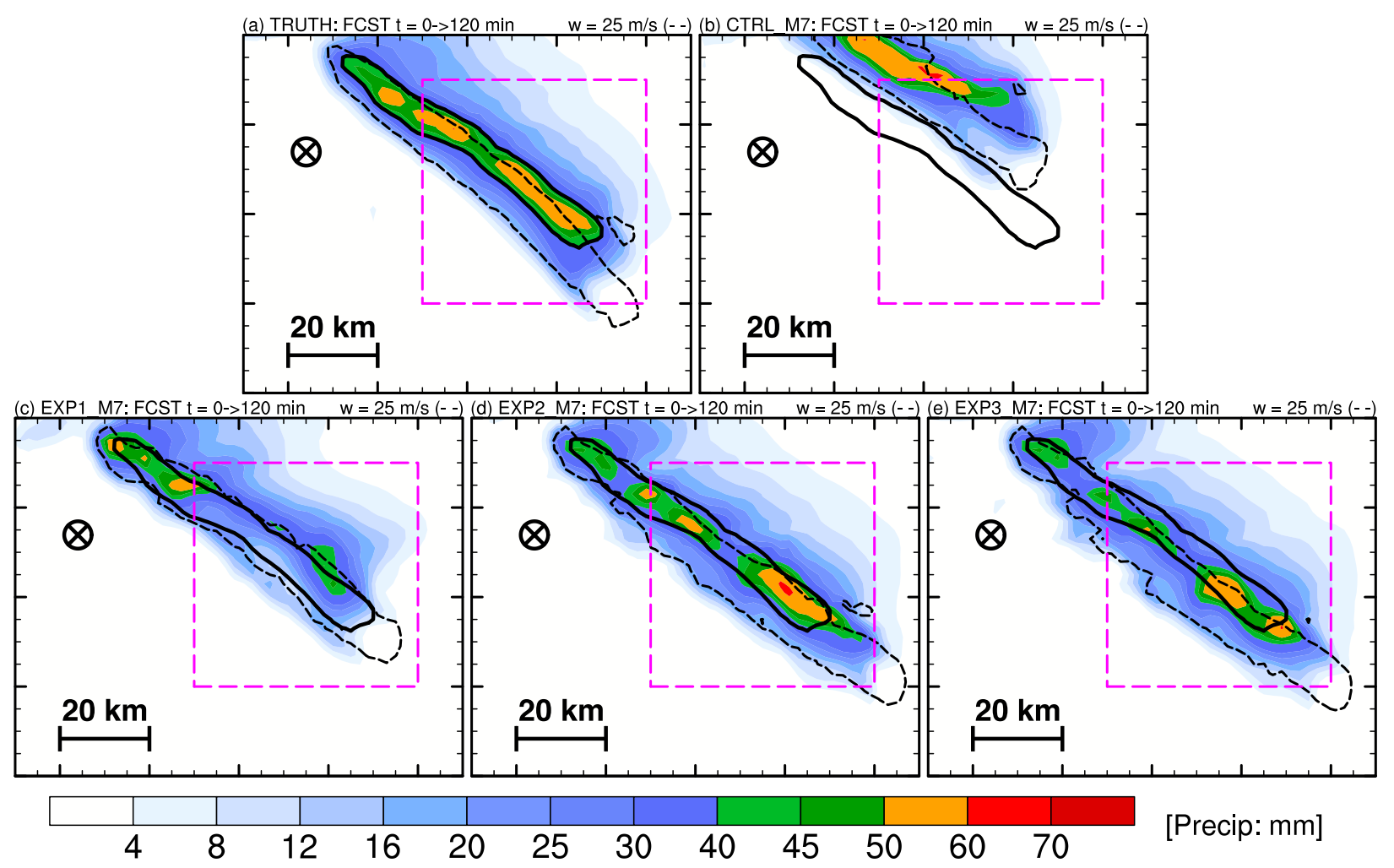

FIG. 10. As in Fig. 9, but for accumulated precipitation (shaded; $\mathrm{mm}$ ) and temporal-height-maximum gridpoint vertical velocity (dashed contour $=25 \mathrm{~m} \mathrm{~s}^{-1}$ ). The black solid contours represent the 40-mm accumulated precipitation of the truth simulation. Magenta-outlined boxes show the area pictured in Fig. 12, below.

$$
\nabla^{2} p_{\mathrm{DL}}^{\prime}=-2 \rho_{0}\left(\frac{\partial u_{0}}{\partial z} \frac{\partial w^{\prime}}{\partial x}+\frac{\partial v_{0}}{\partial z} \frac{\partial w^{\prime}}{\partial y}\right)
$$

We first solve the Poisson equations in Eqs. (5) and (6) numerically to obtain $p_{D}^{\prime}$ and $p_{\mathrm{DL}}^{\prime}$ for given appropriate boundary conditions (Coffer and Parker 2015; Wang et al. 2016). Then, the residual can be treated as the nonlinear dynamic perturbation pressure (i.e., $p_{\mathrm{DNL}}^{\prime}=p_{D}^{\prime}-p_{\mathrm{DL}}^{\prime}$ ) (Coffer and Parker 2015). Last, the components of the total dynamic pressure acceleration, the linear dynamic VPPGF $\left[-\left(1 / \rho_{0}\right)\left(\partial p_{\mathrm{DL}}^{\prime} / \partial z\right)\right.$, hereinafter LD_VPPGF], and nonlinear dynamic VPPGF $\left[-\left(1 / \rho_{0}\right)\left(\partial p_{\mathrm{DNL}}^{\prime} / \partial z\right)\right.$, hereinafter NLD_VPPGF], respectively, are calculated.

The VPPGF terms, vertical velocities, and accumulated precipitation fields are shown in Fig. 12 for the truth simulation and member 7 of EXP1, EXP2, and EXP3, respectively. The low-level updraft distributions in EXP2 and EXP3 resemble those in the truth simulation much more than EXP1 (Fig. 12). For a curved hodograph, lateral updraft propagation is mainly due to the linear dynamic forcing that is directed upward on the flank of an updraft. The upwarddirected nonlinear dynamic forcing is usually a maximum near the updraft axis (Markowski and Richardson 2010).
From Fig. 12, a strong upward-directed LD_VPPGF is located on the east flank of the updraft and a downward-directed LD_VPPGF is on the west flank of the updraft, which promotes the lateral updraft eastward propagation. The spatial distribution of LD_VPPGF in EXP2 and EXP3 is more similar to the truth compared to EXP1, especially the location of strong LD_VPPGF $\left(>9 \times 10^{-3} \mathrm{~m} \mathrm{~s}^{-2}\right.$, marked by white triangles). These diagnoses indicate assimilating environmental clear-air radial velocity can correct forecast environment winds (e.g., environmental wind shear) and then correct the lateral updraft propagation through the LD_VPPGF term, thereby making the supercell propagation, maintenance, and track closer to the truth (Figs. 9 and 10). As for NLD VPPGF, as shown in the last column of Fig. 12, for all experiments in general the strong upward-directed NLD_VPPGF is located close to the updraft core rather than on the updraft flank (Fig. 12). In other words, the NLD_VPPGF and vertical velocity fields are approximately in phase (collocated), which can accelerate vertical motions and maintain updrafts. In general, all experiments display this collocation. The magnitude and spatial patterns of NLD_VPPGF in 
(a) TRUTH @ 95 min

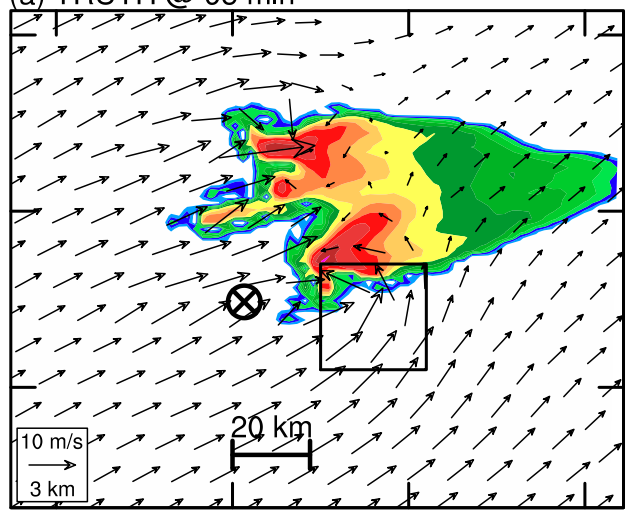

(c) EXP1 M7: 30-min FCST from $\mathrm{t}=65 \mathrm{~min}$
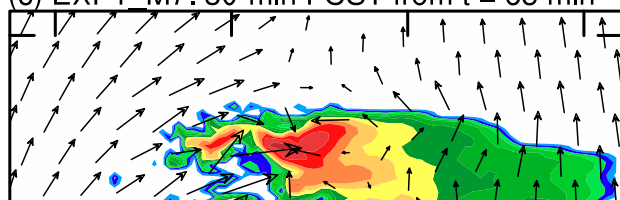

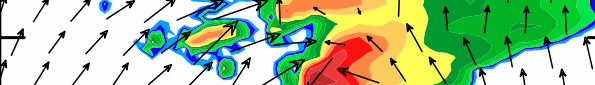

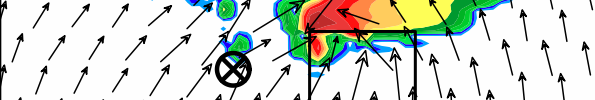

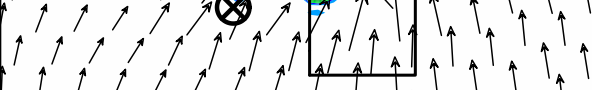

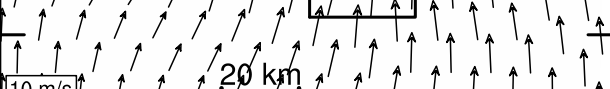

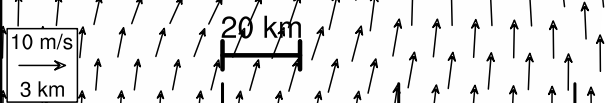

(e) EXP3 M7: 30-min FCST from $\mathrm{t}=65 \mathrm{~min}$
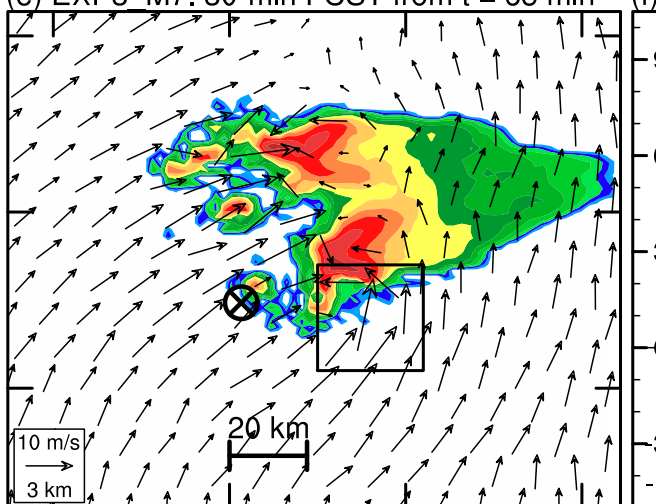

FIG 11. Horizontal wind vectors and radar reflectivity

( (a) the truth simulation and member 7 of (b) CTRL, (c) EXP1, (d) EXP2, and (e) EXP3. Also shown are (f) the hodographs averaged within the black-outlined boxes shown in (a)-(e) from 1 to $6 \mathrm{~km}$ at $500-\mathrm{m}$ intervals.

(b) CTRL M7: 30-min FCST from $\mathrm{t}=65 \mathrm{~min}$
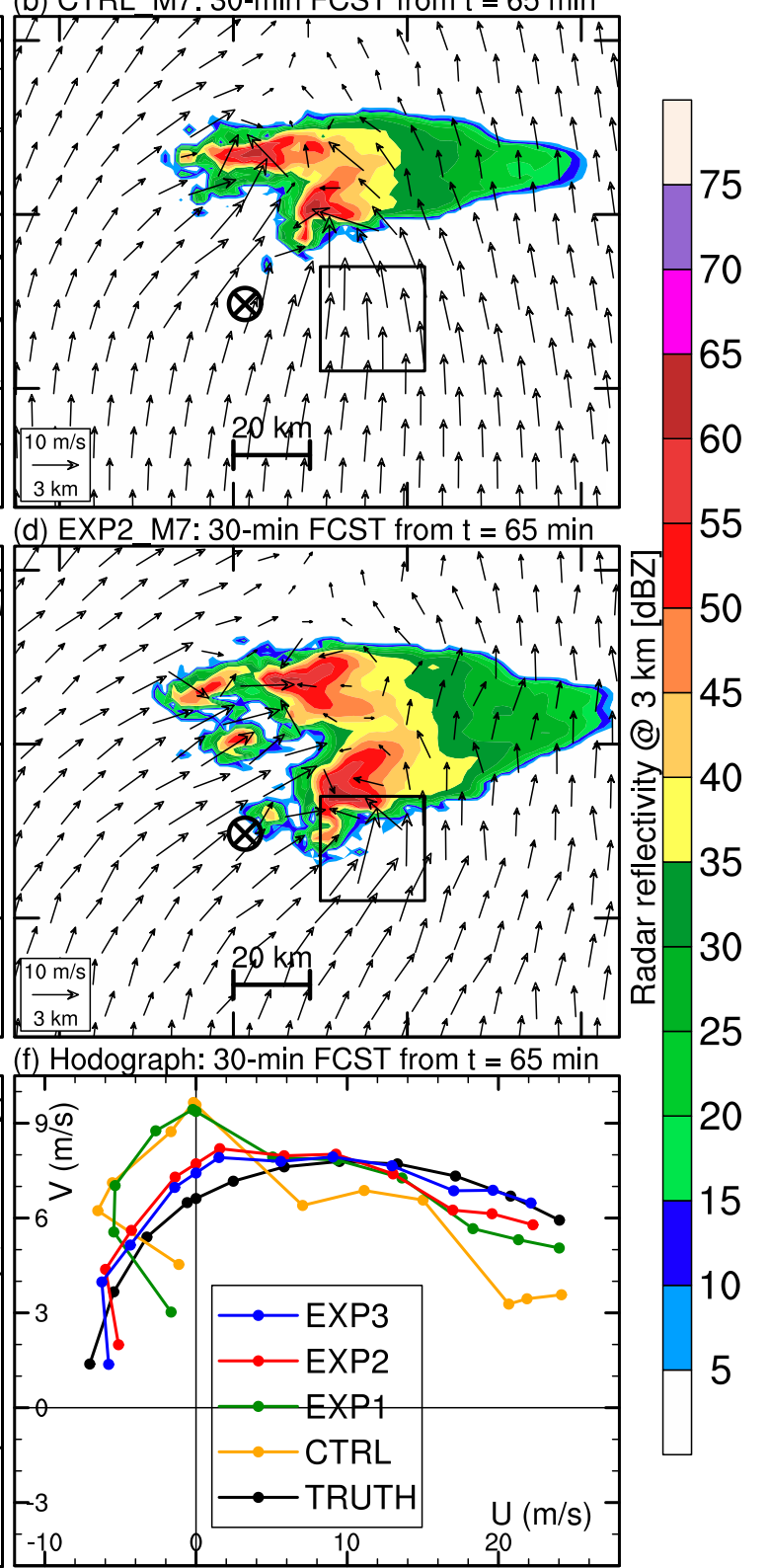

\section{the}

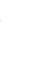


LD_VPPGF @ 1 km

LD_VPPGF @ 3 km

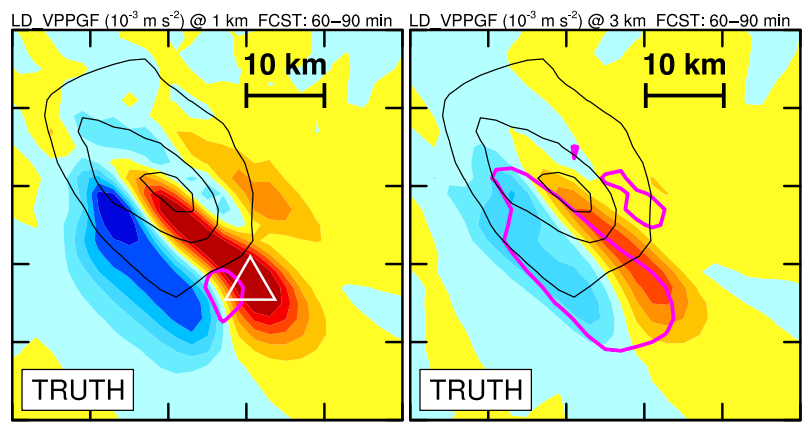

LD VPPGF $\left(10^{-3} \mathrm{~m} \mathrm{~s}^{-2}\right) @ 1 \mathrm{~km}$ FCST: $60--90 \mathrm{~min} L \mathrm{LD}$ VPPGF $\left(10^{-3} \mathrm{~m} \mathrm{~s}^{-2}\right) @ 3 \mathrm{~km}$ FCST:60--90 min

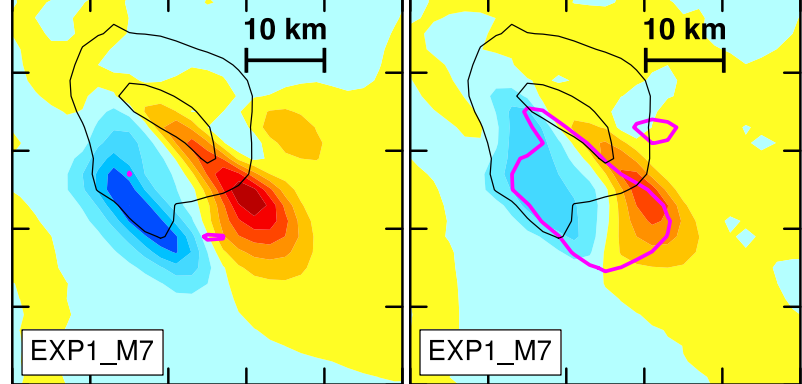

LD VPPGF $\left(10^{-3} \mathrm{~m} \mathrm{~s}^{-2}\right) @ 1 \mathrm{~km}$ FCST: $60--90 \mathrm{~min} L D$ VPPGF $\left(10^{-3} \mathrm{~m} \mathrm{~s}^{-2}\right) @ 3 \mathrm{~km}$ FCST: 60--90 min

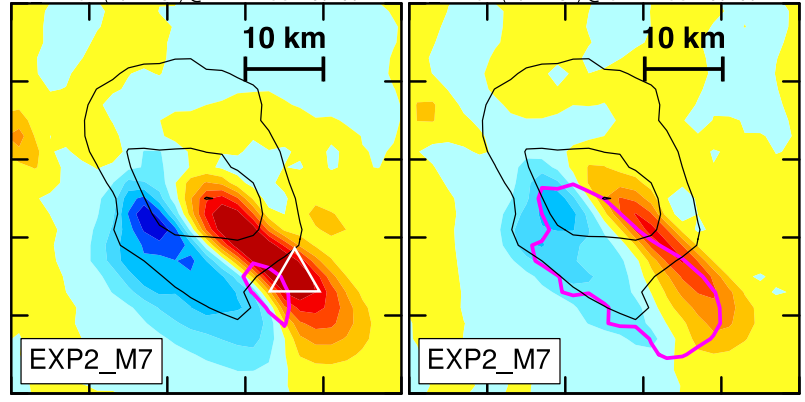

LD VPPGF $\left(10^{-3} \mathrm{~m} \mathrm{~s}^{-2}\right) @ 1 \mathrm{~km}$ FCST: 60--90 min LD VPPGF $\left(10^{-3} \mathrm{~m} \mathrm{~s}^{-2}\right) @ 3 \mathrm{~km}$ FCST: 60--90 min

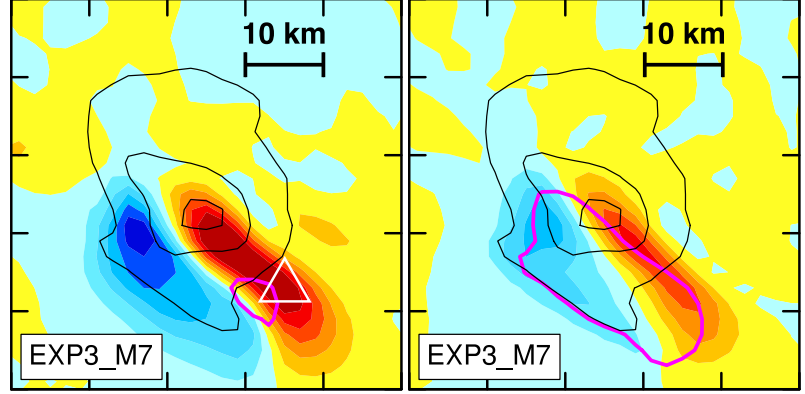

NLD_VPPGF @ 1 km NLD_VPPGF @ 3 km

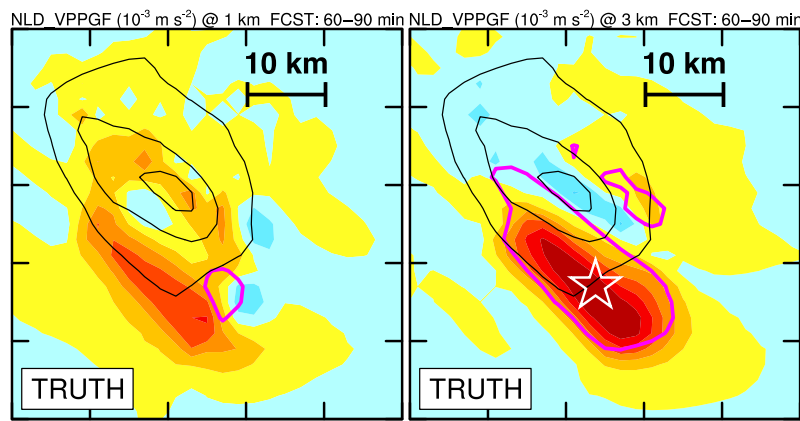

NLD VPPGF $\left(10^{-3} \mathrm{~m} \mathrm{~s}^{-2}\right) @ 1 \mathrm{~km}$ FCST: $60--90 \mathrm{~min} \operatorname{NLD}$ VPPGF $\left(10^{-3} \mathrm{~m} \mathrm{~s}^{-2}\right) @ 3 \mathrm{~km}$ FCST: $60--90 \mathrm{~min}$

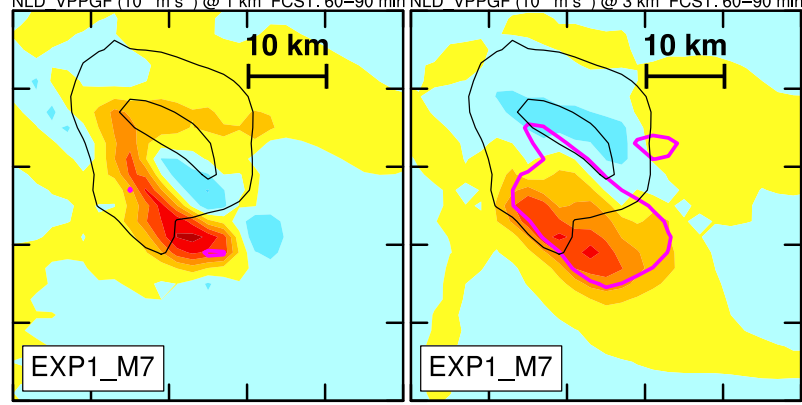

NLD VPPGF $\left(10^{-3} \mathrm{~m} \mathrm{~s}^{-2}\right) @ 1 \mathrm{~km}$ FCST: 60--90 min NLD VPPGF $\left(10^{-3} \mathrm{~m} \mathrm{~s}^{-2}\right) @ 3 \mathrm{~km}$ FCST: $60-90 \mathrm{~min}$

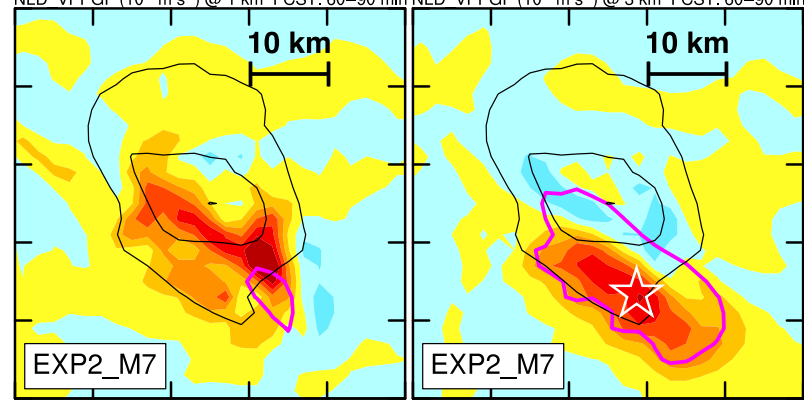

NLD VPPGF $\left(10^{-3} \mathrm{~m} \mathrm{~s}^{-2}\right) @ 1 \mathrm{~km}$ FCST: 60--90 min NLD VPPGF $\left(10^{-3} \mathrm{~m} \mathrm{~s}^{-2}\right) @ 3 \mathrm{~km}$ FCST: $60--90 \mathrm{~min}$

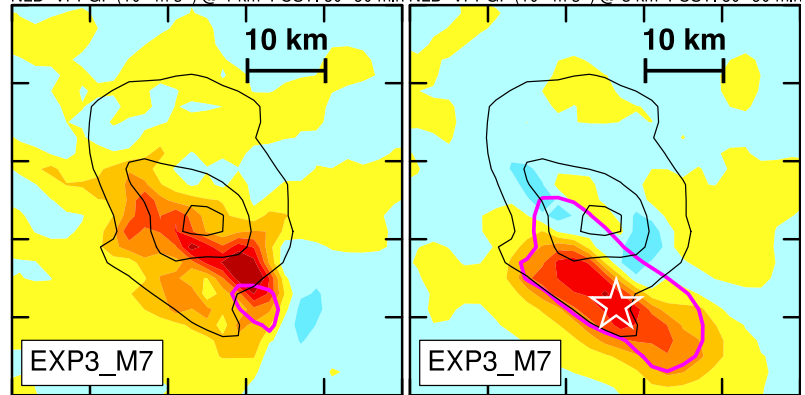

VPPGF $\left(10^{-3} \mathrm{~m} \mathrm{~s}^{-2}\right)$

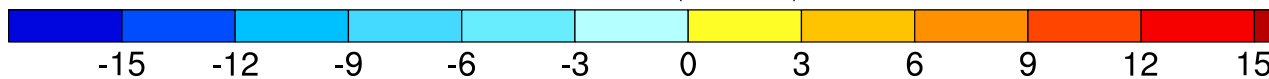

FIG. 12. Temporal-averaged (left),(left center) linear and (right center),(right) nonlinear dynamic VPPGF (shaded; $10^{-3} \mathrm{~m} \mathrm{~s}^{-2}$ ) and vertical velocity (magenta contours: $2 \mathrm{~m} \mathrm{~s}^{-1}$ ) at 1- and 3-km heights and 30-min accumulated precipitation (black contours: 10, 30, and $50 \mathrm{~mm}$ ) of (top) the truth simulation and member 7 of (top middle) EXP1, (bottom middle) EXP2, and (bottom) EXP3 during the period from $t=125$ to $155 \mathrm{~min}$ (forecast period 60-90 min). The pictured area is shown by the magenta-outlined boxes in Fig. 10. Tick marks are included every $10 \mathrm{~km}$. The white triangles and stars show important features that are discussed in the text. 
summing both the advective component and the propagation component, the motion vector of a right-moving supercell $\left(\mathbf{V}_{\mathrm{RM}}\right)$ is given by

$$
\mathbf{V}_{\mathrm{RM}}=\mathbf{V}_{\text {mean }}+D \frac{\mathbf{V}_{\text {shear }} \times \hat{\mathbf{k}}}{\left|\mathbf{V}_{\text {shear }}\right|},
$$

where $\mathbf{V}_{\text {mean }}$ is the mean wind vector, $\mathbf{V}_{\text {shear }}$ is the vertical wind shear vector, and $\mathrm{D}$ represents the deviation magnitude orthogonal to the right of the vertical wind shear vector from the mean wind. In the ID method, $\mathbf{V}_{\text {mean }}$ is estimated by 0-6-km non-pressure-weighted mean wind, $\mathbf{V}_{\text {shear }}$ is calculated by the difference between the $5.5-6-\mathrm{km}$ mean wind and the $0-0.5-\mathrm{km}$ mean wind, and D is equal to $7.5 \mathrm{~m} \mathrm{~s}^{-1}$. From Figs. 7-9, the storm paths are adjusted toward the west in EXP2 and EXP3 relative to EXP1, especially in the early forecast period. It may be mainly attributed to the correction of background winds by assimilating clear-air radial velocity observations. Figure 13 shows $\mathbf{V}_{\text {mean }}, \mathbf{V}_{\mathrm{RM}}$, and mean supercell motions $\left(\mathbf{V}_{\mathrm{UH}}\right)$ of truth simulation, member 7 of EXP1, EXP2, and EXP3, respectively. The zonal component of mean wind in EXP1 is stronger than the truth simulation and is weakened in EXP2 and EXP3 by assimilating clear-air radial velocity observations (Fig. 13). Although the $\mathbf{V}_{\mathrm{RM}}$ in all experiments are similar to each other, directions of $\mathbf{V}_{\mathrm{RM}}$ in EXP2 and EXP3 are closer to that of truth while $\mathbf{V}_{\mathrm{RM}}$ in EXP1 deviates to the left of the $\mathbf{V}_{\mathrm{RM}}$ in truth. The $\mathbf{V}_{\mathrm{UH}}$ in all experiments are characterized by features that are similar to those of $\mathbf{V}_{\mathrm{RM}}$ (Fig. 13). It indicates that assimilating clear-air radial velocity observations can correct storm motion.

\section{Summary}

To evaluate the potential value of assimilating PAR clear-air radial velocity observations for supercell forecasts, observing system simulation experiments are conducted in this study. High-temporal-resolution synthetic PAR observations of a splitting supercell thunderstorm are created using the Weather Research and Forecasting Model. These observations are assimilated over a 5-min period in different stages of the storm using ensemble Kalman filter. The main findings are summarized as follows:

1) Assimilating environmental clear-air radial velocity in addition to clear-air reflectivity improves forecasts across different stages of the supercell's life cycle. The improvement begins about $30 \mathrm{~min}$ into forecasts that are initialized at different stages. Moreover, assimilating the environmental clear-air radial velocity at 5-min intervals provides forecasts with comparable

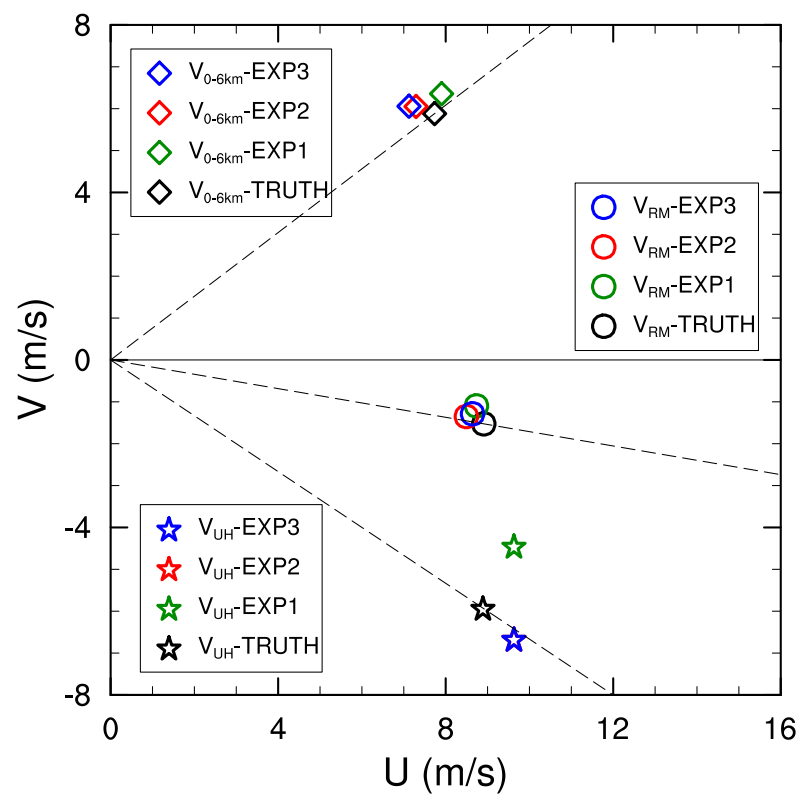

FIG. 13. The 0-6-km non-pressure-weighted mean wind ( $\mathbf{V}_{0-6 \mathrm{~km}}$; diamonds) and the predicted right-moving supercell motion $\left(\mathbf{V}_{\mathrm{RM}}\right.$; circles) estimated by using the ID method and hodographs (Fig. 11f) at $t=95 \mathrm{~min}$ (30-min forecast) of the truth simulation (black) and member 7 of EXP1 (green), EXP2 (red), and EXP3 (blue), respectively. The mean supercell motions ( $\mathbf{V}_{\mathrm{UH}}$; stars) estimated using maximum UH centers at $t=65 \mathrm{~min}$ ( 0 -min forecast) and $t=110 \mathrm{~min}$ (45-min forecast) are also given. Note that $\mathbf{V}_{\mathrm{UH}}$ in EXP2 and EXP3 are equal and therefore overlap in the figure. The dashed lines go through the origin $(0,0)$ and the centers of $\mathbf{V}_{0-6 \mathrm{~km}}$, $\mathbf{V}_{\mathrm{RM}}$, and $\mathbf{V}_{\mathrm{UH}}$ in the truth simulation, respectively.

skill as those at 1-min intervals in this idealized case study.

2) Errors in near-storm environmental winds decrease after assimilating clear-air radial velocity, and the benefit is carried out to the forecast beyond the 60 -min lead time. The increased accuracy of environment wind fields also improves the accuracy of the wind fields within precipitation regions during the forecast due to the interaction between the storm and its environment.

3) After assimilating clear-air radial velocity, the probability forecasts for updraft helicity and precipitation increase up to $30 \%-40 \%$ within the corresponding swath of truth simulation. Such improvement is attributed to the improved storm track forecast and the increased duration of rotating updrafts in the forecast.

4) Further diagnostics are performed through comparing the linear and nonlinear VPPGFs among all experiments. It is revealed that assimilating environmental clear-air radial velocity improves the linear dynamic forcing estimation which leads to better forecast of the lateral updraft propagation. 
This improvement allows the supercell to propagate continuously and more closely to the track of the truth simulation. Meanwhile, assimilating the environmental clear-air radial velocity observations enhances vertical acceleration within the supercell updraft, and therefore better maintains updrafts through the improved nonlinear dynamic forcing estimation. As a result, the size and duration of strong updrafts in the experiments assimilating clear-air radial velocity more closely match the truth simulations. In addition, the correction of background winds by assimilating clear-air radial velocity observations also contribute to more accurate storm motion.

In conclusion, this study, to our knowledge, is the first to explore the impact of assimilating PAR-like clear-air radial velocity observations on a short-term forecast of a supercell thunderstorm. As an initial study of this topic, we perform OSSEs without model error. The positive impact of assimilating PAR clear-air radial velocity observations is also only demonstrated with a single idealized supercell case initialized with a horizontally homogeneous base state. OSSEs with model error included, using more complex environmental conditions or considering different types of convective modes, should be considered in the future. In addition, future studies should examine the effects of radar location and how well the radar sampling of low-level winds affects the benefits of clear-air data assimilation. What's more, it is also promising to assimilate clear-air velocity data to target a particular feature, such as misocyclone occurrence (Friedrich et al. 2005).

Acknowledgments. This work was supported by NA160AR4320115. The authors appreciate Editor Dr. Glen Romine and three anonymous reviewers for their comments that contributed to improving the paper. The authors acknowledge high-performance computing support from the OU Supercomputing Center for Education and Research (OSCER) at the University of Oklahoma (OU) and Cheyenne (https://doi.org/10.5065/ D6RX99HX) provided by NCAR's Computational and Information Systems Laboratory, sponsored by the National Science Foundation. We appreciate discussion with Drs. Mark Weber and Yongming Wang.

\section{REFERENCES}

Anderson, J. L., 2001: An ensemble adjustment Kalman filter for data assimilation. Mon. Wea. Rev., 129, 2884-2903, https://doi.org/10.1175/1520-0493(2001)129<2884:AEAKFF> 2.0.CO;2.

—, T. Hoar, K. Raeder, H. Liu, N. Collins, R. Torn, and A. Avellano, 2009: The Data Assimilation Research Testbed:
A community facility. Bull. Amer. Meteor. Soc., 90, 1283-1296, https://doi.org/10.1175/2009BAMS2618.1.

Benjamin, S. G., and Coauthors, 2016: A North American hourly assimilation and model forecast cycle: The Rapid Refresh. Mon. Wea. Rev., 144, 1669-1694, https://doi.org/10.1175/ MWR-D-15-0242.1.

Bowden, K. A., P. L. Heinselman, D. M. Kingfield, and R. P. Thomas, 2015: Impacts of phased-array radar data on forecaster performance during severe hail and wind events. Wea. Forecasting, 30, 389-404, https://doi.org/10.1175/WAF-D-1400101.1.

Bunkers, M. J., B. A. Klimowski, J. W. Zeitler, R. L. Thompson, and M. L. Weisman, 2000: Predicting supercell motion using a new hodograph technique. Wea. Forecasting, 15, 61-79, https://doi.org/10.1175/1520-0434(2000)015<0061: PSMUAN $>2.0$.CO;2.

—, J. S. Johnson, L. J. Czepyha, J. M. Grzywacz, B. A. Klimowski, and M. R. Hjelmfelt, 2006: An observational examination of long-lived supercells. Part II: Environmental conditions and forecasting. Wea. Forecasting, 21, 689-714, https://doi.org/10.1175/WAF952.1.

Chilson, P. B., and Coauthors, 2019: Moving towards a network of autonomous UAS atmospheric profiling stations for observations in the earth's lower atmosphere: The 3D Mesonet concept. Sensors, 19, 2720, https://doi.org/10.3390/s19122720.

Chipilski, H. G., X. Wang, and D. P. Parsons, 2020: Impact of assimilating PECAN profilers on the prediction of bore-driven nocturnal convection: A multiscale forecast evaluation for the 6 July 2015 case study. Mon. Wea. Rev., 148, 1147-1175, https:// doi.org/10.1175/MWR-D-19-0171.1.

Cintineo, R. M., and D. J. Stensrud, 2013: On the predictability of supercell thunderstorm evolution. J. Atmos. Sci., 70, 1993 2011, https://doi.org/10.1175/JAS-D-12-0166.1.

Clark, A. J., J. Gao, P. T. Marsh, T. Smith, J. S. Kain, J. Correia, M. Xue, and F. Kong, 2013: Tornado pathlength forecasts from 2010 to 2011 using ensemble updraft helicity. Wea. Forecasting, 28, 387-407, https://doi.org/10.1175/WAF-D-1200038.1.

Coffer, B. E., and M. D. Parker, 2015: Impacts of increasing lowlevel shear on supercells during the early evening transition. Mon. Wea. Rev., 143, 1945-1969, https://doi.org/10.1175/ MWR-D-14-00328.1.

Coniglio, M. C., S. M. Hitchcock, and K. H. Knopfmeier, 2016: Impact of assimilating preconvective upsonde observations on short-term forecasts of convection observed during MPEX. Mon. Wea. Rev., 144, 4301-4325, https://doi.org/ 10.1175/MWR-D-16-0091.1.

Degelia, S. K., X. Wang, D. J. Stensrud, and A. Johnson, 2018: Understanding the impact of radar and in situ observations on the prediction of a nocturnal convection initiation event on 25 June 2013 using an ensemble-based multiscale data assimilation system. Mon. Wea. Rev., 146, 1837-1859, https:// doi.org/10.1175/MWR-D-17-0128.1.

,-- , and -2019 : An evaluation of the impact of assimilating AERI retrievals, kinematic profilers, rawinsondes, and surface observations on a forecast of a nocturnal convection initiation event during the PECAN field campaign. Mon. Wea. Rev., 147, 2739-2764, https://doi.org/10.1175/MWR-D-18-0423.1.

Dowell, D. C., and L. J. Wicker, 2009: Additive noise for stormscale ensemble data assimilation. J. Atmos. Oceanic Technol., 26, 911-927, https://doi.org/10.1175/2008JTECHA1156.1.

, F. Zhang, L. J. Wicker, C. Snyder, and N. A. Crook, 2004: Wind and temperature retrievals in the 17 May 1981 Arcadia, 
Oklahoma, supercell: Ensemble Kalman filter experiments. Mon. Wea. Rev., 132, 1982-2005, https://doi.org/10.1175/15200493(2004)132<1982:WATRIT>2.0.CO;2.

— - L. J. Wicker, and C. Snyder, 2011: Ensemble Kalman filter assimilation of radar observations of the 8 May 2003 Oklahoma City supercell: Influences of reflectivity observations on storm-scale analyses. Mon. Wea. Rev., 139, 272-294, https://doi.org/10.1175/2010MWR3438.1.

Friedrich, K., D. E. Kingsmill, and C. R. Young, 2005: Misocyclone characteristics along Florida gust fronts during CaPE. Mon. Wea. Rev., 133, 3345-3367, https://doi.org/10.1175/MWR3040.1.

Gao, J., and D. J. Stensrud, 2012: Assimilation of reflectivity data in a convective-scale, cycled 3DVAR framework with hydrometeor classification. J. Atmos. Sci., 69, 1054-1065, https:// doi.org/10.1175/JAS-D-11-0162.1.

Gaspari, G., and S. E. Cohn, 1999: Construction of correlation functions in two and three dimensions. Quart. J. Roy. Meteor. Soc., 125, 723-757, https://doi.org/10.1002/qj.49712555417.

Hamill, T. M., 1999: Hypothesis tests for evaluating numerical precipitation forecasts. Wea. Forecasting, 14, 155-167, https:// doi.org/10.1175/1520-0434(1999)014<0155:HTFENP > 2.0.CO;2.

Heinselman, P. L., and S. M. Torres, 2011: High-temporal-resolution capabilities of the National Weather Radar Testbed Phased-Array Radar. J. Appl. Meteor. Climatol., 50, 579-593, https://doi.org/10.1175/2010JAMC2588.1.

_ D. S. LaDue, and H. Lazrus, 2012: Exploring impacts of rapidscan radar data on NWS warning decisions. Wea. Forecasting, 27, 1031-1044, https://doi.org/10.1175/WAF-D-11-00145.1.

— — - D. M. Kingfield, and R. Hoffman, 2015: Tornado warning decisions using phased-array radar data. Wea. Forecasting, 30, 57-78, https://doi.org/10.1175/WAF-D-1400042.1.

Hu, M., M. Xue, J. Gao, and K. Brewster, 2006: 3DVAR and cloud analysis with WSR-88D level-II data for the prediction of the Fort Worth, Texas, tornadic thunderstorms. Part II: Impact of radial velocity analysis via 3DVAR. Mon. Wea. Rev., 134, 699721, https://doi.org/10.1175/MWR3093.1.

Huang, Y., and Coauthors, 2018: Forecasting severe convective storms with WRF-based RTFDDA radar data assimilation in Guangdong, China. Atmos. Res., 209, 131-143, https://doi.org/ 10.1016/j.atmosres.2018.03.010.

_ - Y. Liu, Y. Liu, and J. C. Knievel, 2019: Budget analyses of a record-breaking rainfall event in the coastal metropolitan city of Guangzhou, China. J. Geophys. Res. Atmos., 124, 93919406, https://doi.org/10.1029/2018JD030229.

Johnson, A., and X. Wang, 2016: A study of multiscale initial condition perturbation methods for convection-permitting ensemble forecasts. Mon. Wea. Rev., 144, 2579-2604, https:// doi.org/10.1175/MWR-D-16-0056.1.

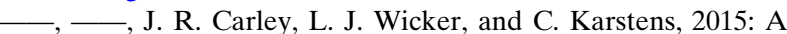
comparison of multiscale GSI-based EnKF and 3DVar data assimilation using radar and conventional observations for midlatitude convective-scale precipitation forecasts. Mon. Wea. Rev., 143, 3087-3108, https://doi.org/10.1175/MWR-D-14-00345.1.

Jones, T. A., and L. J. Wicker, 2014: Using radar reflectivity as a state variable in DART: Is it optimal? 27th Conf. on Severe Local Storms, Madison, WI, Amer. Meteor. Soc., 50, https:// ams.confex.com/ams/27SLS/webprogram/Paper254985.html.

$\longrightarrow$, and — 2015: Radar reflectivity and radial velocity forward operator comparisons in EAKF data assimilation. 37th Conf. on Radar Meteorology, Norman, OK, Amer. Meteor. Soc., 273, https://ams.confex.com/ams/37RADAR/webprogram/ Paper275485.html.
, D. Stensrud, L. Wicker, P. Minnis, and R. Palikonda, 2015: Simultaneous radar and satellite data storm-scale assimilation using an ensemble Kalman filter approach for 24 May 2011. Mon. Wea. Rev., 143, 165-194, https://doi.org/10.1175/MWRD-14-00180.1.

Jung, Y., M. Xue, G. Zhang, and J. M. Straka, 2008: Assimilation of simulated polarimetric radar data for a convective storm using the ensemble Kalman filter. Part II: Impact of polarimetric data on storm analysis. Mon. Wea. Rev., 136, 2246-2260, https://doi.org/10.1175/2007MWR2288.1.

Kain, J. S., and Coauthors, 2008: Some practical considerations regarding horizontal resolution in the first generation of operational convection-allowing NWP. Wea. Forecasting, 23, 931-952, https://doi.org/10.1175/WAF2007106.1.

_ S. R. Dembek, S. J. Weiss, J. L. Case, J. J. Levit, and R. A. Sobash, 2010: Extracting unique information from highresolution forecast models: Monitoring selected fields and phenomena every time step. Wea. Forecasting, 25, 1536-1542, https://doi.org/10.1175/2010WAF2222430.1.

Kerr, C. A., D. J. Stensrud, and X. Wang, 2015: Assimilation of cloud-top temperature and radar observations of an idealized splitting supercell using an observing system simulation experiment. Mon. Wea. Rev., 143, 1018-1034, https://doi.org/ 10.1175/MWR-D-14-00146.1.

— — - and — 2019: Diagnosing convective dependencies on near-storm environments using ensemble sensitivity analyses. Mon. Wea. Rev., 147, 495-517, https://doi.org/10.1175/MWRD-18-0140.1.

Klazura, G. E., and D. A. Imy, 1993: A description of the initial set of analysis products available from the NEXRAD WSR-88D system. Bull. Amer. Meteor. Soc., 74, 1293-1312, https://doi.org/10.1175/1520-0477(1993)074<1293:ADOTIS> 2.0.CO;2.

Limpert, G. L., and A. L. Houston, 2018: Ensemble sensitivity analysis for targeted observations of supercell thunderstorms. Mon. Wea. Rev., 146, 1705-1721, https://doi.org/ 10.1175/MWR-D-17-0029.1.

Liu, S., and Coauthors, 2016: WSR-88D radar data processing at NCEP. Wea. Forecasting, 31, 2047-2055, https://doi.org/ 10.1175/WAF-D-16-0003.1.

Lu, H., and Q. Xu, 2009: Trade-offs between measurement accuracy and resolutions in configuring phased-array radar velocity scans for ensemble-based storm-scale data assimilation. J. Appl. Meteor. Climatol., 48, 1230-1244, https://doi.org/ 10.1175/2008JAMC2009.1

Markowski, P. M., and Y. P. Richardson, 2010: Mesoscale Meteorology in Midlatitudes. John Wiley and Sons, $430 \mathrm{pp}$. , and - 2014: The influence of environmental low-level shear and cold pools on tornadogenesis: Insights from idealized simulations. J. Atmos. Sci., 71, 243-275, https://doi.org/ 10.1175/JAS-D-13-0159.1

McPherson, R. A., and Coauthors, 2007: Statewide monitoring of the mesoscale environment: A technical update on the Oklahoma Mesonet. J. Atmos. Oceanic Technol., 24, 301-321, https://doi.org/10.1175/JTECH1976.1.

Melnikov, V. M., D. S. Zrnić, R. J. Doviak, P. B. Chilson, D. B. Mechem, and Y. L. Kogan, 2011: Prospects of the WSR-88D radar for cloud studies. J. Appl. Meteor. Climatol., 50, 859-872, https://doi.org/10.1175/2010JAMC2303.1.

Mittermaier, M., and N. Roberts, 2010: Intercomparison of spatial forecast verification methods: Identifying skillful spatial scales using the fractions skill score. Wea. Forecasting, 25, 343-354, https://doi.org/10.1175/2009WAF2222260.1. 
Nowotarski, C. J., and P. M. Markowski, 2016: Modifications to the near-storm environment induced by simulated supercell thunderstorms. Mon. Wea. Rev., 144, 273-293, https://doi.org/ 10.1175/MWR-D-15-0247.1.

NRC, 2009: Observing Weather and Climate from the Ground Up-A Nationwide Network of Networks. National Academies Press, 250 pp., https://doi.org/10.17226/12540.

Pan, S., J. Gao, D. J. Stensrud, X. Wang, and T. A. Jones, 2018: Assimilation of radar radial velocity and reflectivity, satellite cloud water path, and total precipitable water for convectivescale NWP in OSSEs. J. Atmos. Oceanic Technol., 35, 67-89, https://doi.org/10.1175/JTECH-D-17-0081.1.

Parker, M. D., 2014: Composite VORTEX2 supercell environments from near-storm soundings. Mon. Wea. Rev., 142, 508529, https://doi.org/10.1175/MWR-D-13-00167.1.

2D mesoscale convective systems. J. Atmos. Sci., 61, 545-567, https://doi.org/10.1175/1520-0469(2004)061<0545:SADOQM> 2.0.CO;2.

Rasmussen, E. N., and D. O. Blanchard, 1998: A baseline climatology of sounding-derived supercell and tornado forecast parameters. Wea. Forecasting, 13, 1148-1164, https://doi.org/ 10.1175/1520-0434(1998)013<1148:ABCOSD>2.0.CO;2.

Roberts, N. M., and H. W. Lean, 2008: Scale-selective verification of rainfall accumulations from high-resolution forecasts of convective events. Mon. Wea. Rev., 136, 78-97, https://doi.org/ 10.1175/2007MWR2123.1.

Rotunno, R., and J. B. Klemp, 1982: The influence of the shearinduced pressure gradient on thunderstorm motion. Mon. Wea. Rev., 110, 136-151, https://doi.org/10.1175/15200493(1982) $110<0136$ :TIOTSI $>2.0$. CO;2.

Schenkman, A. D., M. Xue, A. Shapiro, K. Brewster, and J. Gao, 2011a: The analysis and prediction of the 8-9 May 2007 Oklahoma tornadic mesoscale convective system by assimilating WSR-88D and CASA radar data using 3DVAR. Mon. Wea. Rev., 139, 224-246, https://doi.org/10.1175/2010MWR3336.1.

,,,,---- and,$- 2011 \mathrm{~b}$ : Impact of CASA radar and Oklahoma Mesonet data assimilation on the analysis and prediction of tornadic mesovortices in an MCS. Mon. Wea. Rev., 139, 3422-3445, https://doi.org/10.1175/MWR-D10-05051.1.

$\longrightarrow, \ldots$, and — 2012: Tornadogenesis in a simulated mesovortex within a mesoscale convective system. J. Atmos. Sci., 69, 3372-3390, https://doi.org/10.1175/JAS-D-12-038.1.

Skamarock, W. C., 2004: Evaluating mesoscale NWP models using kinetic energy spectra. Mon. Wea. Rev., 132, 3019-3032, https://doi.org/10.1175/MWR2830.1.

Snyder, C., and F. Zhang, 2003: Assimilation of simulated Doppler radar observations with an ensemble Kalman filter. Mon. Wea. Rev., 131, 1663-1677, https://doi.org/10.1175//2555.1.

Sobash, R. A., and L. J. Wicker, 2015: On the impact of additive noise in storm-scale EnKF experiments. Mon. Wea. Rev., 143, 3067-3086, https://doi.org/10.1175/MWR-D-14-00323.1.

Stensrud, D. J., and J. Gao, 2010: Importance of horizontally inhomogeneous environmental initial conditions to ensemble storm-scale radar data assimilation and very short-range forecasts. Mon. Wea. Rev., 138, 1250-1272, https://doi.org/ 10.1175/2009MWR3027.1.

Sun, J., 2005: Initialization and numerical forecasting of a supercell storm observed during STEPS. Mon. Wea. Rev., 133, 793-813, https://doi.org/10.1175/MWR2887.1.

— , and J. W. Wilson, 2003: The assimilation of radar data for weather prediction. Radar and Atmospheric Science: A
Collection of Essays in Honor of David Atlas, R. M. Wakimoto and R. Srivastava, Eds., Amer. Meteor. Soc., 175-198, https:// doi.org/10.1007/978-1-878220-36-3_7.

— , and H. Wang, 2013: Radar data assimilation with WRF 4D-Var. Part II: Comparison with 3D-Var for a squall line over the U.S. Great Plains. Mon. Wea. Rev., 141, 2245-2264, https://doi.org/10.1175/MWR-D-12-00169.1.

_- and Coauthors, 2014: Use of NWP for nowcasting convective precipitation: Recent progress and challenges. Bull. Amer. Meteor. Soc., 95, 409-426, https://doi.org/10.1175/BAMS-D11-00263.1.

Thompson, G., P. R. Field, R. M. Rasmussen, and W. D. Hall, 2008: Explicit forecasts of winter precipitation using an improved bulk microphysics scheme. Part II: Implementation of a new snow parameterization. Mon. Wea. Rev., 136, 5095-5115, https://doi.org/10.1175/2008MWR2387.1.

Thompson, R. L., R. Edwards, J. A. Hart, K. L. Elmore, and P. Markowski, 2003: Close proximity soundings within supercell environments obtained from the Rapid Update Cycle. Wea. Forecasting, 18, 1243-1261, https://doi.org/10.1175/15200434(2003)018<1243:CPSWSE $>2.0$.CO;2.

Thompson, T. E., L. J. Wicker, and X. Wang, 2012: Impact from a volumetric radar-sampling operator for radial velocity observations within EnKF supercell assimilation. J. Atmos. Oceanic Technol., 29, 1417-1427, https://doi.org/10.1175/JTECH-D12-00088.1.

Tong, M., and M. Xue, 2005: Ensemble Kalman filter assimilation of Doppler radar data with a compressible nonhydrostatic model: OSS experiments. Mon. Wea. Rev., 133, 1789-1807, https://doi.org/10.1175/MWR2898.1.

Wade, A. R., M. C. Coniglio, and C. L. Ziegler, 2018: Comparison of near- and far-field supercell inflow environments using radiosonde observations. Mon. Wea. Rev., 146, 2403-2415, https://doi.org/10.1175/MWR-D-17-0276.1.

Wang, C.-C., B.-K. Chiou, G. T.-J. Chen, H.-C. Kuo, and C.-H. Liu, 2016: A numerical study of back-building process in a quasistationary rainband with extreme rainfall over northern Taiwan during 11-12 June 2012. Atmos. Chem. Phys., 16, 12 359-12 382, https://doi.org/10.5194/acp-16-12359-2016.

Wang, Y., and X. Wang, 2017: Direct assimilation of radar reflectivity without tangent linear and adjoint of the nonlinear observation operator in the GSI-based EnVar system: Methodology and experiment with the 8 May 2003 Oklahoma City tornadic supercell. Mon. Wea. Rev., 145, 1447-1471, https://doi.org/10.1175/MWR-D-16-0231.1.

Weber, M. E., J. Y. N. Cho, J. S. Herd, J. M. Flavin, W. E. Benner, and G. S. Torok, 2007: The next-generation multimission U.S. surveillance radar network. Bull. Amer. Meteor. Soc., 88, 1739-1752, https://doi.org/10.1175/BAMS-88-11-1739.

Weisman, M. L., and R. Rotunno, 2000: The use of vertical wind shear versus helicity in interpreting supercell dynamics. J. Atmos. Sci., 57, 1452-1472, https://doi.org/10.1175/15200469(2000)057<1452:TUOVWS>2.0.CO;2.

Wurman, J., D. Dowell, Y. Richardson, P. Markowski, E. Rasmussen, D. Burgess, L. Wicker, and H. B. Bluestein, 2012: The Second Verification of the Origins of Rotation in Tornadoes Experiment: VORTEX2. Bull. Amer. Meteor. Soc., 93, 1147-1170, https:// doi.org/10.1175/BAMS-D-11-00010.1.

Xiao, Q., Y.-H. Kuo, J. Sun, W.-C. Lee, E. Lim, Y.-R. Guo, and D. M. Barker, 2005: Assimilation of Doppler radar observations with a regional 3DVAR system: Impact of Doppler velocities on forecasts of a heavy rainfall case. J. Appl. Meteor., 44, 768-788, https://doi.org/10.1175/JAM2248.1. 
Yu, T.-Y., M. B. Orescanin, C. D. Curtis, D. S. Zrnić, and D. E. Forsyth, 2007: Beam multiplexing using the phased-array weather radar. J. Atmos. Oceanic Technol., 24, 616-626, https://doi.org/10.1175/JTECH2052.1.

Yussouf, N., and D. J. Stensrud, 2010: Impact of phased-array radar observations over a short assimilation period: Observing system simulation experiments using an ensemble Kalman filter. Mon. Wea. Rev., 138, 517-538, https://doi.org/10.1175/ 2009MWR2925.1.

E. R. Mansell, L. J. Wicker, D. M. Wheatley, and D. J. Stensrud, 2013: The ensemble Kalman filter analyses and forecasts of the 8 May 2003 Oklahoma City tornadic supercell storm using single- and double-moment microphysics schemes. Mon. Wea. Rev., 141, 3388-3412, https:// doi.org/10.1175/MWR-D-12-00237.1.

Zrnić, D. S., and Coauthors, 2007: Agile-beam phased array radar for weather observations. Bull. Amer. Meteor. Soc., 88, 17531766, https://doi.org/10.1175/BAMS-88-11-1753.

, S. E. Koch, R. D. Palmer, M. E. Weber, K. D. Hondl, G. M. McFarquhar, and M. H. Jain, 2019: How an agile-beam polarimetric phased-array radar can add to the observing capabilities of the NWS. Phased Array Radar Symp., Phoenix, AZ, Amer. Meteor. Soc., 2.3, https://ams.confex.com/ams/ 2019Annual/meetingapp.cgi/Paper/351777. 